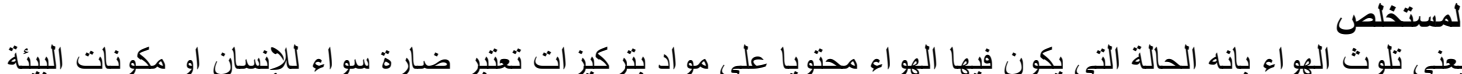

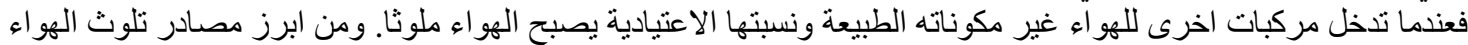

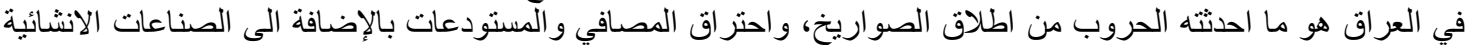

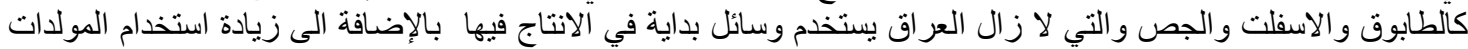

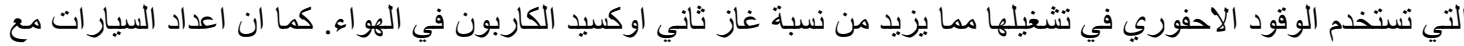

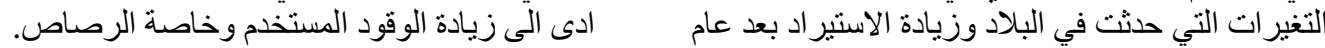

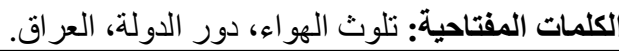

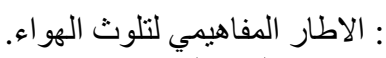

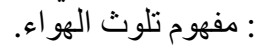

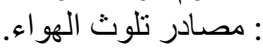

: اضر ار تلوث الهو اءو الهواء.

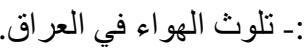

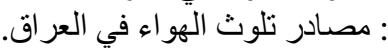

: استر اتيجية الدولة للحفاظ على البيئة من تلوث ألوث

الهو اء في العراق. - مات.

منهجية البحث:

فرضية الدراسة: رغم الجهود المبذولة من قبل الدولة بعد

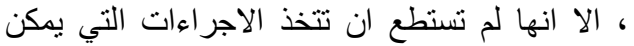

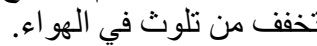

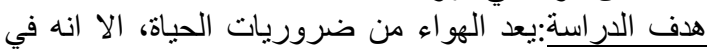

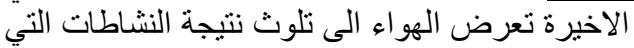

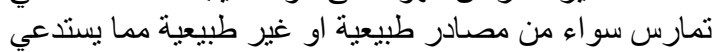

الوقوف على هذه النشاطات ومدى التلوث الذئي الذي نجم عنها.

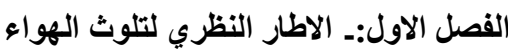

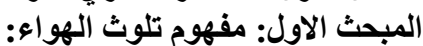

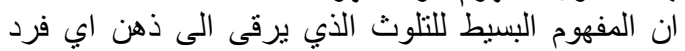

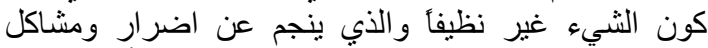
صحية للإنسان بل والكائنات الحية و العالم بأكمله الستينات من القرن العشرين

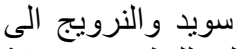

، و اقترحت عقد مؤتمر دولي للنظر في حماية

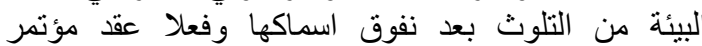

المقدمة

نحن نستنشق الهواء في كل لحظة وفي كل يوم الهواء

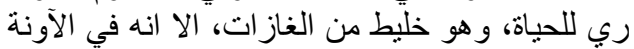

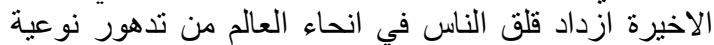

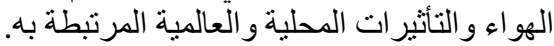

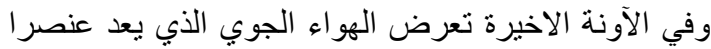

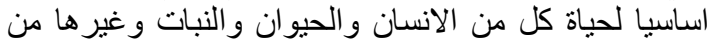

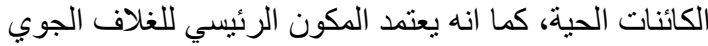

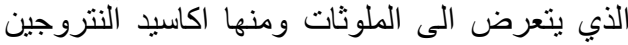

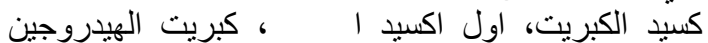

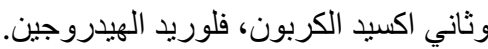

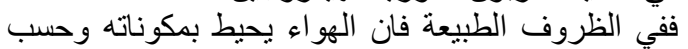

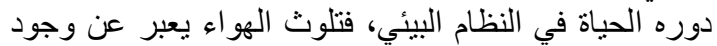

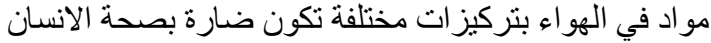

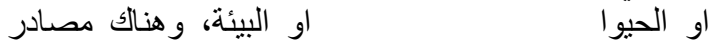
لتلوث الهواء منها مصادر طبيعة لا دخل للإنسان فيها

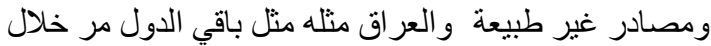

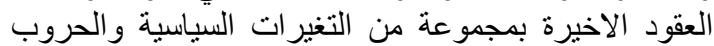

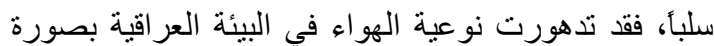

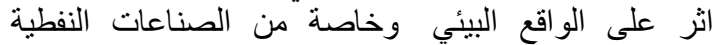
والانشائية والكيميائية والتي التئي اتصفت بأنها مصادر ثابنابنة

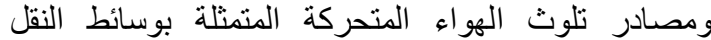

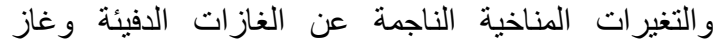

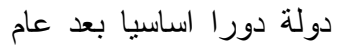

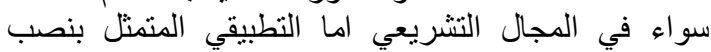

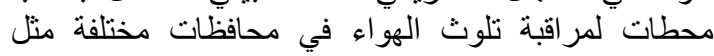

\footnotetext{
Corresponding author:

Dr. Muntder Fadil Saad

$\bowtie$ muntadarfadhel@yahoo.com
} 


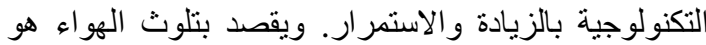

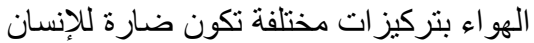
و الحيوان او النبات او التربة او البيئة

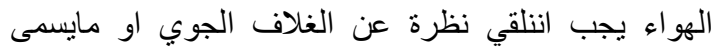

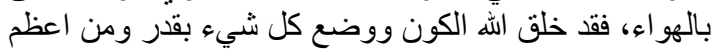

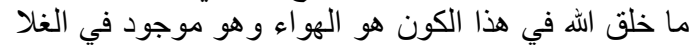
الجوي بقدر موزون على شكل غاز الك ات بنسب طبيعة متفلاونة.
ستوكهولم عام .وكانت هنالك ثلاث انواع رئيسية البيئي منها تلوث الهو أهواء و والمباه

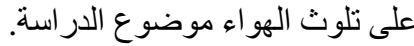
حيث يعتبر الهواء من اساسيات الحياه فانقطاعه لدقائق الأن يعد كافيا لهلاك الانسان من النيانيات

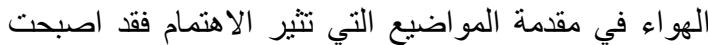

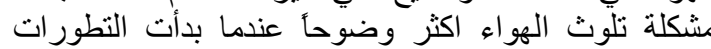

\begin{tabular}{|c|c|c|c|c|c|}
\hline التركيز \% & الرمز الكيميائي & الغازات & التركيز \% & الرمز الكيميائي & الغازات \\
\hline . & $\mathrm{H} 2$ & الهليوم & 78,09 & N2 & النتروجين \\
\hline , & Ch4 & الميثان & , & $\mathrm{O} 2$ & الاوكسجين \\
\hline , & So2 & ثاني اوكسيد الكبريت & , & $\mathrm{Ar}$ & \\
\hline , & $\mathrm{NO} 2$ & ثاني اوكسبد النتروجين & , & $\mathrm{Co} 2$ & ثاني اوكسيد الكاربون \\
\hline & & & & $\mathrm{N} 2$ & النيون \\
\hline & & & , & KR & الكرتيون \\
\hline & & & , & $\mathrm{H} 2$ & الهيدروجين \\
\hline & & & , & $\mathrm{N} 2 \mathrm{O}$ & ول اوكسيد النتروجين \\
\hline & & & , & $\mathrm{CO}$ & اول اوكسيد الكاربون \\
\hline & & & & O3 & \\
\hline
\end{tabular}

جدول رقم ( (1): مكونات الهواء الجاف غير الملوث و النسب الحجمية للتر اكيز.

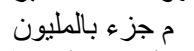

- ـ فتحي حسين الامين، عوض ابر اهيم زبلح، تلوث الهو اء و المخاطر البيئية الناتجة عن عو ادم المركبات في مدينة مصر اته،

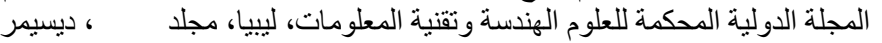

فان الغلاف الذي يحيط بالأرض يتكون من طبقات

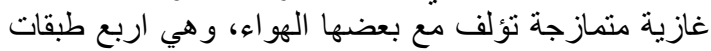

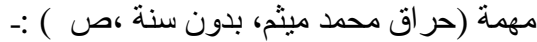

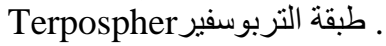

وهي الطبقة التي بعيش فيها الانسان وهي طبقة

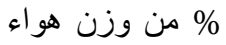

الغلاف الجوي كله، وترتفع هذه الطبقة الى مسافة

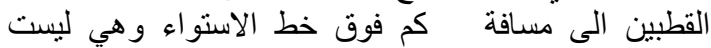

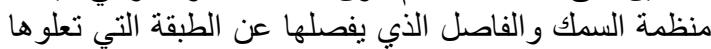
تسمى التروبوسفير وتتميز طبقة التربوسفير باحتو ائها على تلى الفي الفي

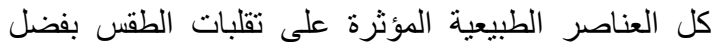

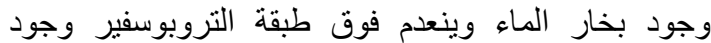

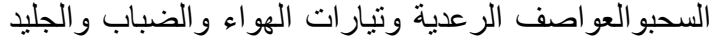
وتتناقص بها درجة الحرارة الرئ بمعدل مئوية لكل كيلو مثر. stratospher طبقة الستروسئر مثنير.

وتمتد هذه الطبقة من خط النّر التربوسفير الى ارتفاع

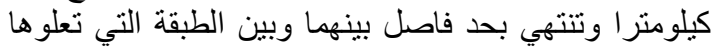

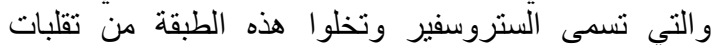

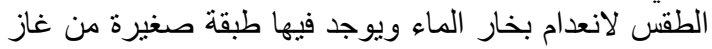

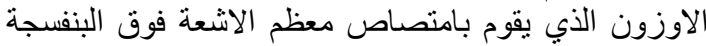

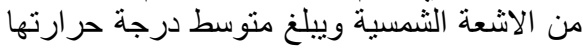
مئوية تحت الصفر الصنة الصنية

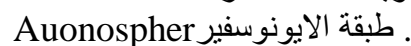

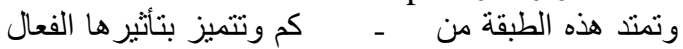

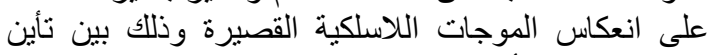

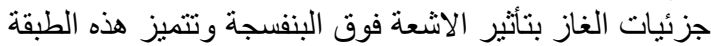

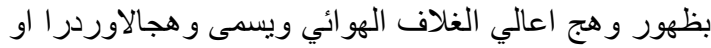

حيث نجد ان الهواء النقي غير الملوث هو الذي يكون

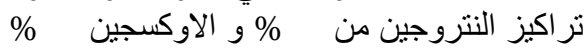
\% 0,9 و الباقي عبارة عن تر اكيز مختلفة النسب.

يتكون الغلاف الجوي من مزيج من الغازات التي \% 99,9)

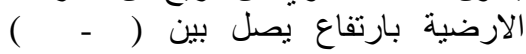

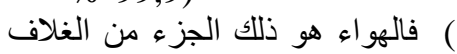

الجوي الذي يقسم الى اربع طبقات (تلوث الهو اء؛، -): (

ط طبقة السترروسفير .

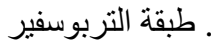

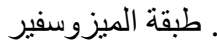
و طبقة الثروموسفير الثبزير ل و الثكل التالي يوضحت هذه

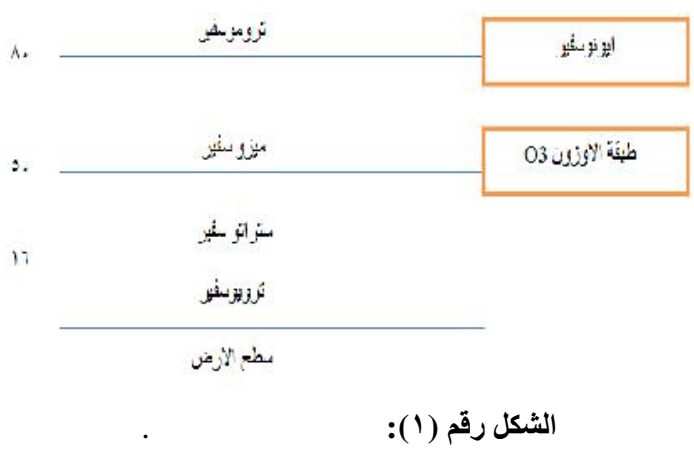


الحية الاوكسجين، واذا زادت نسبة ثنائي اوكسيد الكاربون

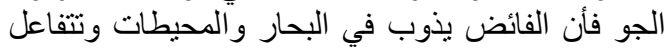

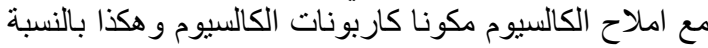

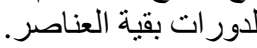

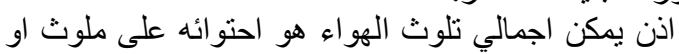

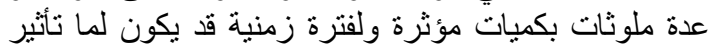

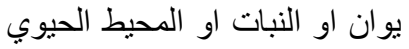

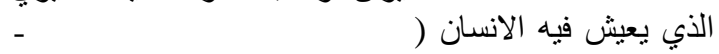

).وقد عرفته منظمة الصحة العالمية الصية بانه الحالة التي يكون

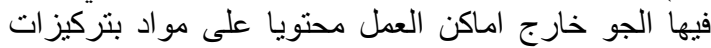

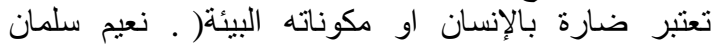

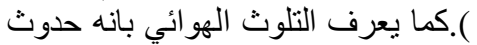

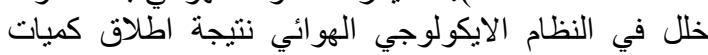

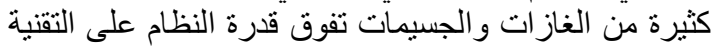

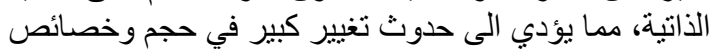

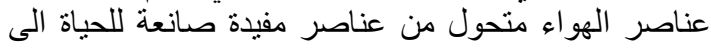

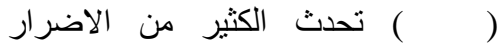

كما عرفه المجلس الاوربي في اعلانه الصادر في

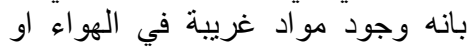
حدوث تغير هام في نسب المواد المكونة له ويترتب علئ فيها

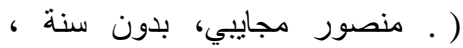

الوهج القطبي و التي تتقسم الى طبقتين فرعيتين هما طبقة بين . طبقة الثروموسفير.

يمتد من حدود الايونوسفير الى عشر الى ات الالاف من الكيلو

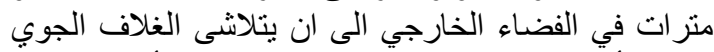

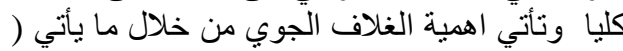

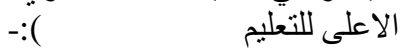
. يحمي الارض من الاشعة الكونية الضارة) ). . يحتوي على الغاز ات الاساسية للحياة(الاوكسجين اكسيد الكربون، بخار الماء).

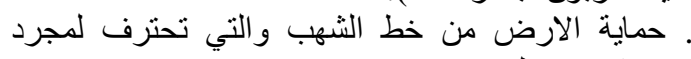

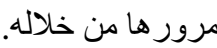
• تتم فيه كافة مظاهر الطقس ورله الـ . يحافظ على درجة حر ارة الارض المفله المناسبة للحياة. . يعكس الموجات الصوتية و المرئية.

( ) يمكن القول ان طبة التة التروبوسفير

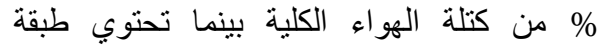

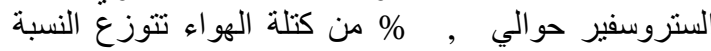

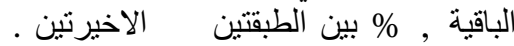

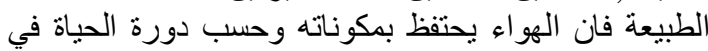

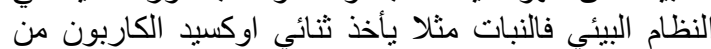
الجو ويحتفظ بالكاربون ويطلق الاوكسجين ونتنفس الكائنات

\begin{tabular}{|c|c|c|}
\hline المواصفات الثانوية & المواصفات الاولية & \multirow[t]{2}{*}{ الملوث وفترة التعرض } \\
\hline l & 1 & \\
\hline نفس المو اصفات الاولية & $(1$ & \multirow[t]{2}{*}{ ادي اوكسيد الكاربون/ } \\
\hline نفس المو اصفات الاولية & $(1$ & \\
\hline نفس المو اصفات الاولية & 0.24 & اكاسيد النتروجين/ \\
\hline $\begin{array}{c}0,02 \\
0,11\end{array}$ & $\begin{array}{c}0,03 \\
0,14\end{array}$ & اكاسيد الكبريت/ \\
\hline نفس المو اصفات الاولية & 0,24 & الهدروكربونات/ \\
\hline $\begin{array}{l}-- \\
---\end{array}$ & $\begin{array}{l}-- \\
---\end{array}$ & / \\
\hline نفس المو اصفات الاولية & 1,5 & الرصاص في الهو اء/ \\
\hline
\end{tabular}

Vesilind,p,a,pejrce,j,jweiner,R,f,, enviramental pollution and control, third edition, butterworth- : Heinemann,boston 1990

سينقلها الانسان و الحيوان و النبات و الجماد وغيرها

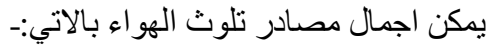
:- من المصادر الطبيعة.

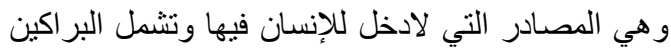

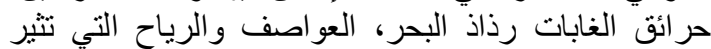
الاتربة والتحليل الحيوي والنشاط البكتيري والنيات والمستشفيات

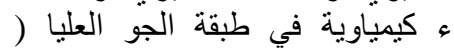

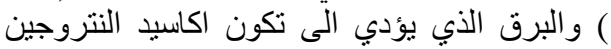

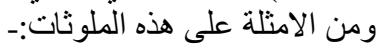

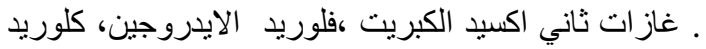
الايدروجين المتصاعد من البر اكين المفطريه.
ان المواصفات الصادرة عن الجهات البيئية المعتمدة عالميا

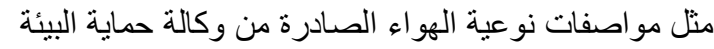

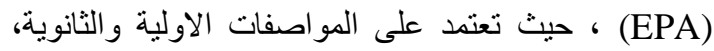

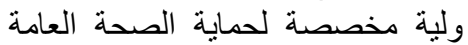

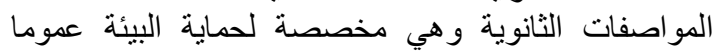

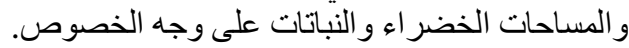

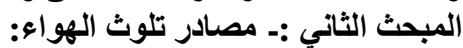

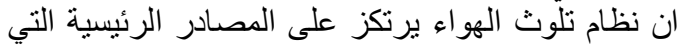

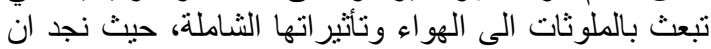

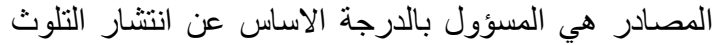
في الهواء بفعل الظروف الجوية والفيزية الائية والكيميائية والتي التياري 
ـ جسيمات دقيقة وهي التي تكون الدخان ومن بينها دقائق

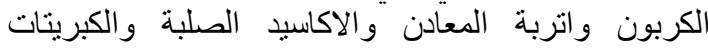

و عادة ما تترسب الجسيمات الكبيرة بالقرب من مصدر الإبر

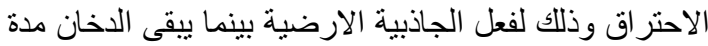

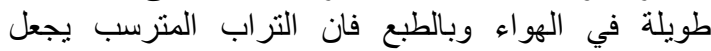

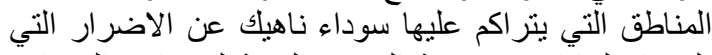

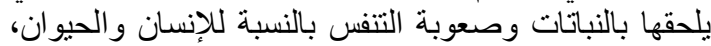

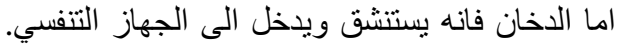
حرق الوقود يؤدي الى تكوين مركبات اخرى ولئ غازية سامة التية

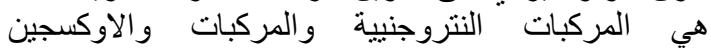

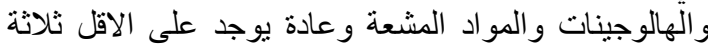
مصادر رئيسية لاحتر اق الوقود وهيني:-

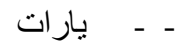
تمثل السيارات المصدر الرئيسي لتلوت الهواء حيث ان

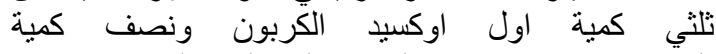

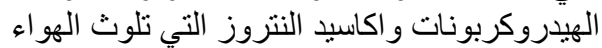

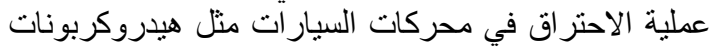

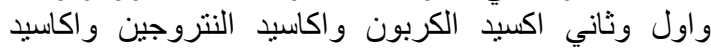

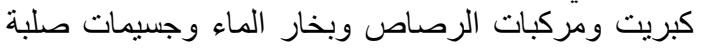
ولعمل الانبعانات الناتجة عن المركبات يتحكم فيها وليهات

(ديزل، بنزين)

تنتج عنها العديد

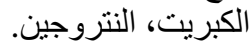

ـ اكاسيد النتروجين الناتجة عن التفريغ الكهربائي للسحب الر عدية.

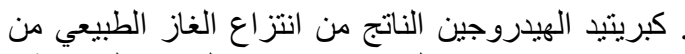
جوف الارض او بسبب البر اكين او تو اجد البكتريا الكبريتئية.

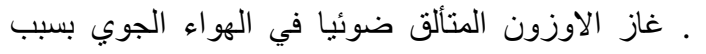

تساقط الاتربة المختلفة عن الثهب والنيازك الى طبقات. السطحية.

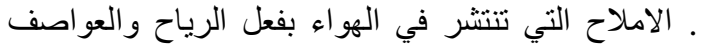

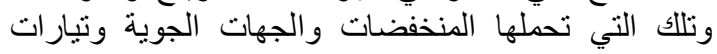
.

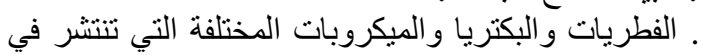

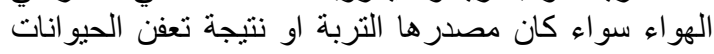
و الطيور الميته واءواء لفضلات.

وصخور القترة الارضية الناتجة عنتأين لـ بفعل الاشعة الكونية.

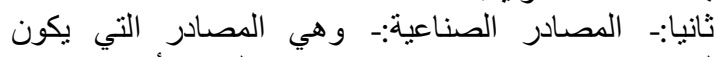

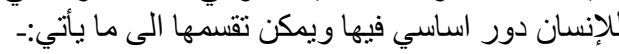

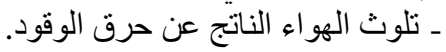

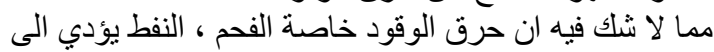

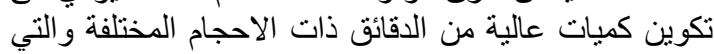

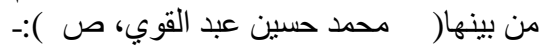
. جسيمات كبيرة وهي التي تكون مايشبه التراب و واهمها

\begin{tabular}{|c|c|c|}
\hline محرك الديزل & محرك البنزين & المادة الملوثة \\
\hline & & ـ ثناني اكسيد الكربون \\
\hline , & , & ـ ثاني اكسيد الكبريت \\
\hline , & , & . اكاسيد النتروجين \\
\hline , & , & . اول اكسيد الكربون \\
\hline , & , & . \\
\hline , & , & هيدروكربونات غير محترقة \\
\hline--- & , & . \\
\hline
\end{tabular}

ومراكز حلج وغزل ونسيج القطن ومصانع البلاستيك

مخلفات تحدث تلوثا للهو اء بالإضافة الى ما تنتجها من ملوثات ناتجة من احتراق الوقود كالصناعات الصات الكيميائية

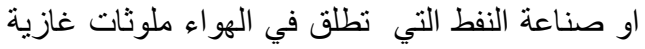

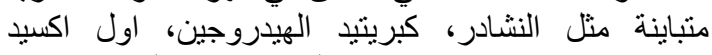

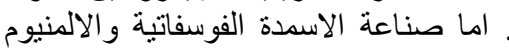

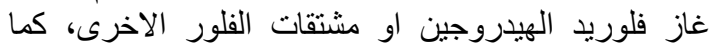

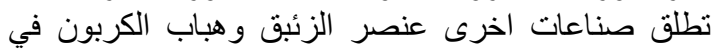
الجو بكميات كبيرة جدا في المدن بكميات كبيرة جدئ جدا في في في في
اذن يتضح من خلال الجدول اعلاه ان اول وثاني اكسيد

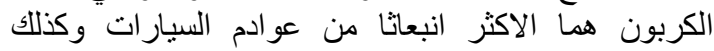

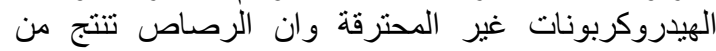
محركات البنزين و لا ينتج من محركات الدير الديزل - محطات القوى الكهربائية

وتنتج من المحطات كميات كبيرة من المونة المواد الملوثية وكميات كبيرة من المواد الهيدروكربونية غير المير المحترقة المبنة وغاز اول اكسيد - - مغل - العمليات الصناعية المختلفة

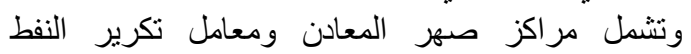
ومصانع المواد الكيمياوية ومصانع الورق و السكر والزجاج 


$$
\text { ـ الفلور وفلوريد الهيدروجين: }
$$

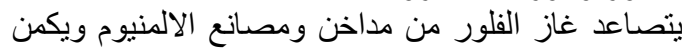

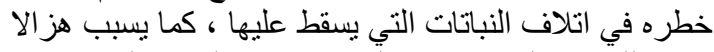

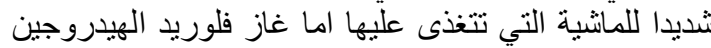

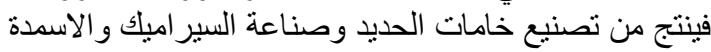
وغاز فلوريد الهيدروجين غاز سام شديد السمية مهيج

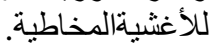

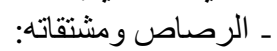

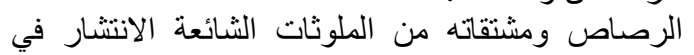

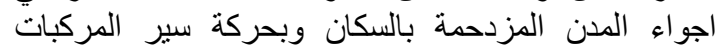

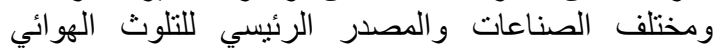

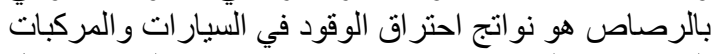

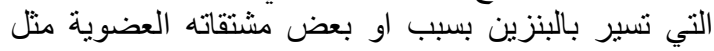

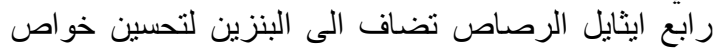

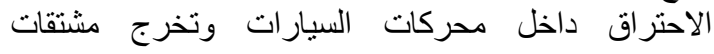
السامة التي نتر اكم في نخاع عظام الحيوانات والى نقص

$$
\begin{aligned}
& \text { الذهني عند الاطفال بالإضافة الى تشوهات في المو اليد. }
\end{aligned}
$$

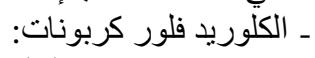

هو مركبات عضوية ثابته كيميائيا تحتوي على على عنصري

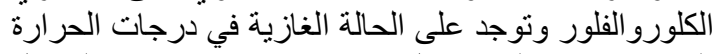

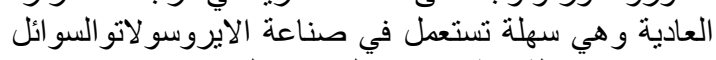
كثلاجة واجهزة ألتكيف و المبردات.

$$
\text { ـ الهيدروكربونات: }
$$

هي مركبات عضوية تتكون من عنورئات الفربري الكربون

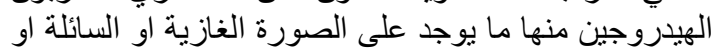

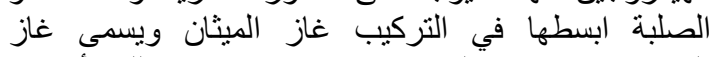

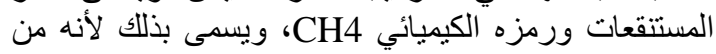

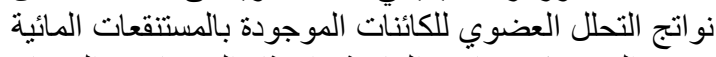
ومن الهيدروكربونات الغازية الايثانو البروبان والبئن البيوتان

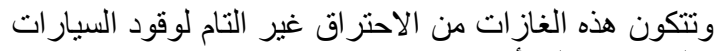

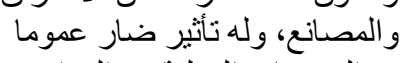

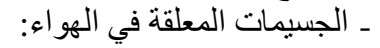

يقصد بها الجسيمات المعلقة في الهواء سواء كانت صلبة

وتتنج من مصادر طبيعة كالرياح و الاعاصير و البر اكين او وإي

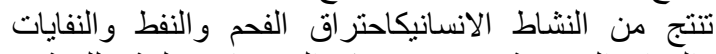

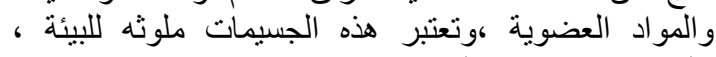
فالسناج هو نوع من الهباب SOOT ويتكون من حيبات دقيقة

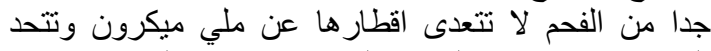

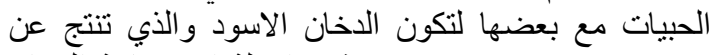

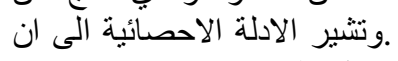

التأثيرات الصحية للجسيمات بمكن ان تحدث التش

No2, So2

dr.Geoffmorgan,dr.Binjalaludin ) ,dr.vickysheppeard ,(2005,p9-10

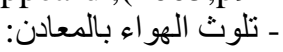

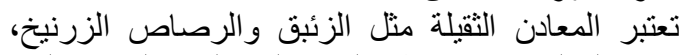

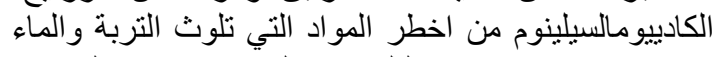
ن الهم مصادر هذا التلوث مخلفات ونفايات المصانع

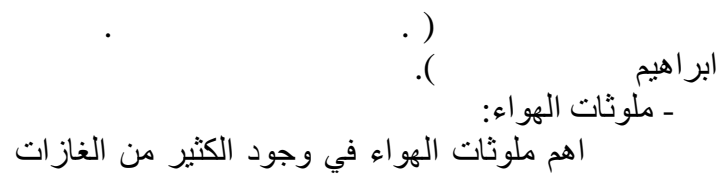

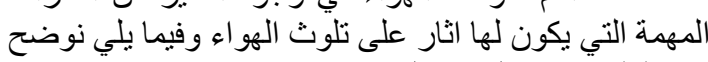

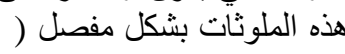

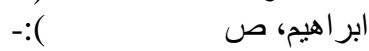

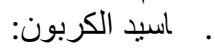

تشمل اكاسيد الكربون غاز ات ثاني اكسيد الكربون واول

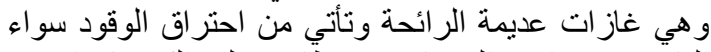

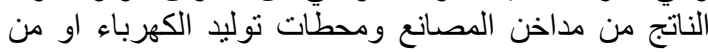

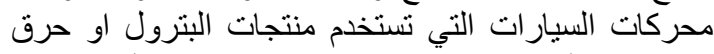

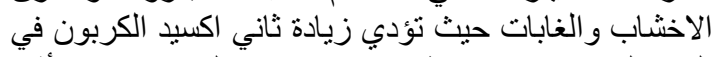

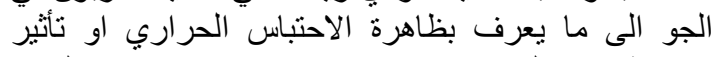

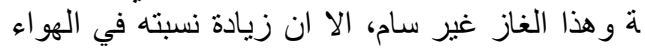

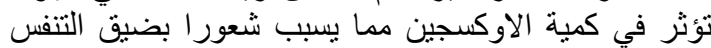
وقد تؤدي الزيادة الكثيرة الى الاختناق والحد الامن من هذا لئن

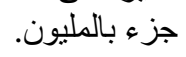

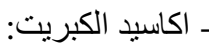

تشمل اكاسيد الكبريت ثاني اكسيد الكبريت وثالثا اكسيد الكبريت وهي تنتج استاسا من عمليات الاحتر القاق التي يستعمل

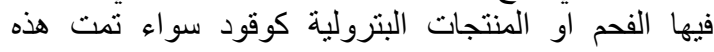

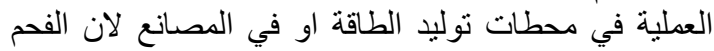
يحتوي نسبة عالية من الكبريت على صوليد الورة مركبات كبريتية \% ,

مشتقات البترول المستخدمة كوقود في محطات توليد الطاقة

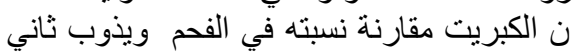

اكسيد كبريت المندفع في الهو اء في بخار الماء الجوبي الجوي مكونتا

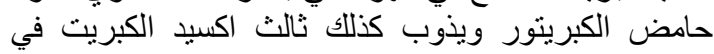
بخار الماء الجوي مكونا حامض الكبريتيك لكئك مكونا الامطار

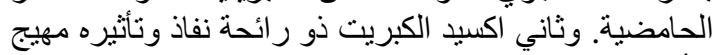

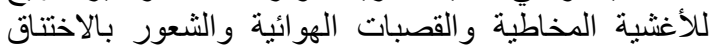

$$
\text { جزء في المليون بـ }
$$

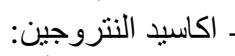

تتكون اكاسيد النتروجين من اتحاد النتروجين البروجين

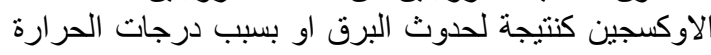

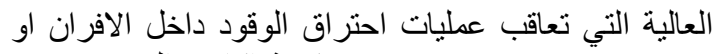

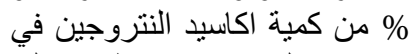

الجو من الاحتراق داخل محركات السيار ات ومحطات توليد

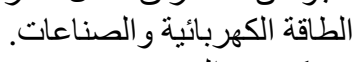
ـ كبريتيد الهيدروجين:

يوجد غاز كبريتيد الهيدروجين في كثيرة من المياه المعدنية

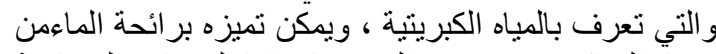

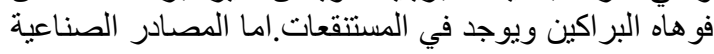

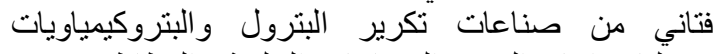

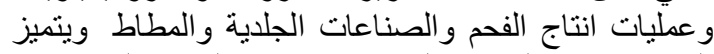

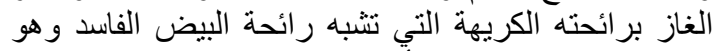

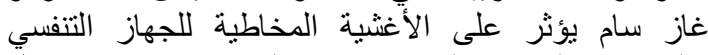
و العصبي و التفكير و التركيز وتهيج العين و الانف وقد يصل 
وصهر الدعادن واحتراق الفحم وعوادم السيارات ويمن تحديد الحدود القصوى لملوثات الهو اء الخارجي. ومبيداتالآفات التي تحتوي على عنصر الزرنيخ.

\begin{tabular}{|c|c|c|}
\hline مدة التعرض & الحد الاقصى & ثاني اكسيدر الكبري \\
\hline & $\begin{array}{l}\text { l } \\
\text { I }\end{array}$ & اول اكسيد الكربون \\
\hline & & ثاني اكسيد النتروجين \\
\hline & & لجسيمات العالقة مقاسه \\
\hline & & الجسيمات العالقة الكلية \\
\hline & & الجسيمات العددية \\
\hline
\end{tabular}

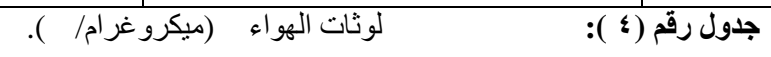

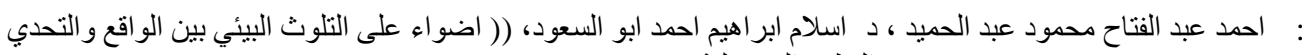

و النظرة المستقبلية)

الهوائي في بعض المناطق الصناعية مما بزيد معه تراكيز

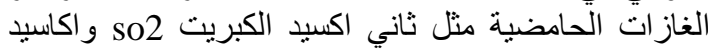

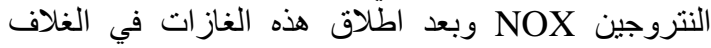
الجوي يتم تحويلها الى كبرينات ونترات وات والتي تتحد مع الماء التهاء لكبريتيك و الهيدروكلوريك التخفضة

ذاذ او قطقصية (طبقة جليدية رقيقه) او ثلج او امطار مكونه

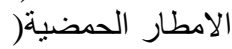
احمد حسن الطيب، ومحمد عبد السلام الطاهر ). وتنتج عن الامطار الحمضية اثار

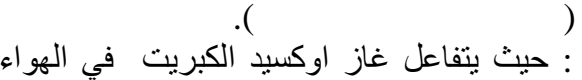
الثيخ،

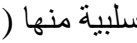
ليكون ايروسو لات الكبريت و وعند استنشاقها تؤدي الى التهاب التهبي وحساسيه الانف والقصبات مع ربو قصبي تحسبي وفي تفاقم ـ الدقائق العالقة المحتوية على غاز ات ثاني اوكسيد الكبريت

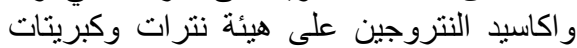

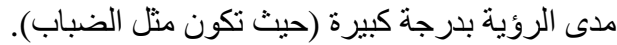
ـ البيئية: تؤُثر على البيئة من خلال تغير التئ التركيب الكيميائي

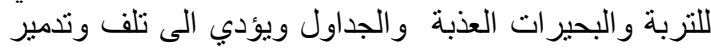
الاشجار والثروة السمكية و الكائنات الحية الكجية التهرية.

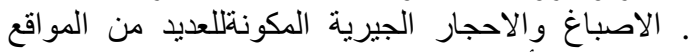

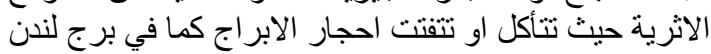
وكنيسة وستمنتر وتاج محل في الهند. لالترن

ينتج الاوزون من عمليات الاكسدة الكهروكيميائية وان

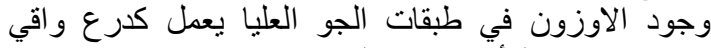

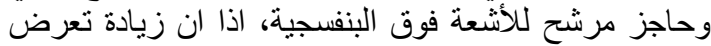

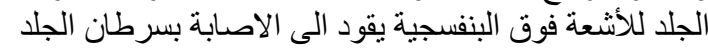
ويتكون الاوزون في الطبقة الجوية العليا (الستراتوسفير ) لالجيلية عندما تقوم الاشعة فوق البنفسجية بتحطيم الاوكسجين الجزئي
المبحث الثالث: الاثار السلبية لتلوث الهواء على الرغم من وجود مشاكل موقعيه في تلوث الثاء الهواء

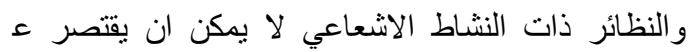
منطقة جغر افية محددة من غير ها لأناعيا الكرة الارضية هو الكية الكودة حركة الكتل الهوائية، واستمرار انطلاق ملوثات ثابتة بيئيا

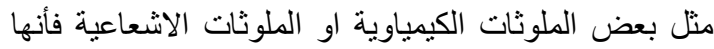

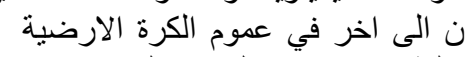

الى طبقات مختلفة الارتفاع في الغلاف الجوي الكرة مسببه اضرار الاربة

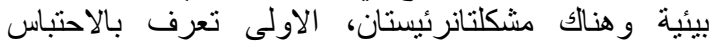

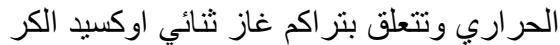
، و الثانية تعرف بمشكلة طبقة

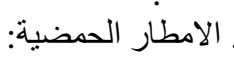

بدأت الدراسات على مايسمى بالأمطار الحمضية منذ بداية

الستينات من هذا القرن، والامطار الحمضية مشكلة ظهرت

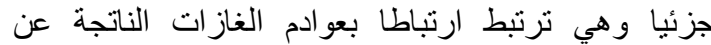

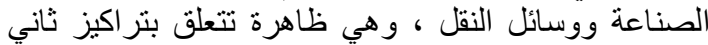

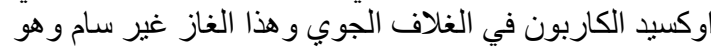

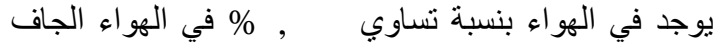
وغير الملوث اي في المناطق النائية عن الآنشطة البشرية وهذا الغاز هو اسأس ديمومه الانتاج الغذائي. ومن اسباب تكون الامطار الحامضية حرق الخئية الوقود

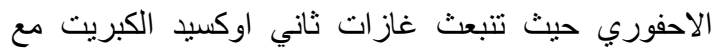
اكاسيد النتروجين لتتفاعل في الجو مع الماءي التهاء والاوكسجين المؤكسد حيث تكون مركبات حامضية مختلفة مكونه مزيجا

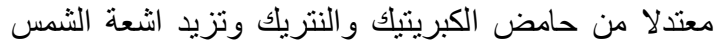
من سرعة او معدل هذه التفاعلات لتسقط هذه المركبات على التى 


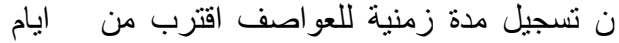

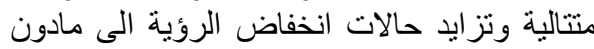

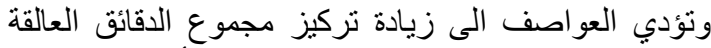

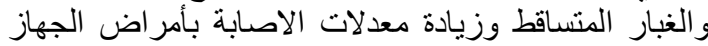

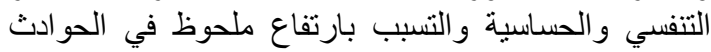

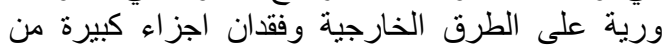

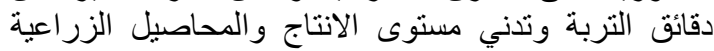

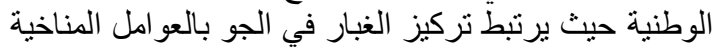

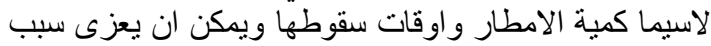

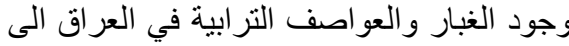

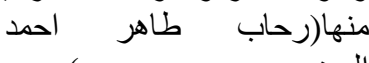
الدين، وقوق عه ضمن المناطق الصحر اوية.

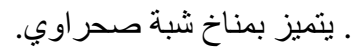

. يتصف بمديات فصلية ويومية كبيرة جدا بدرجات الحرارة

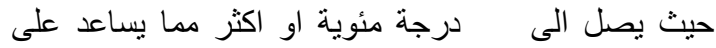
تفتيت التربة وبالتالي يسهل رفعها بو اسطة الرياح. ـ قاتلة الامطار السنوية المنساقطة.

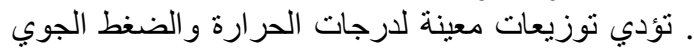
في مختلف فصول السنة الى زيادة سرعة الرياح وعدم الرئم استخر اريتها. و تمركز منخفض جوي فوق منطقة الخليج العربي

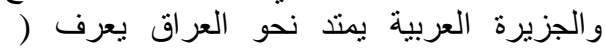
) ييقى طيلة ايام الصيف حيث يسبب هبوب الرياح

ـ ازدياد طول النهار صيفا والذي يؤدي الى زيادة كمية

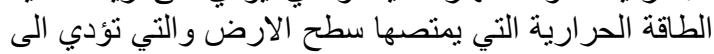

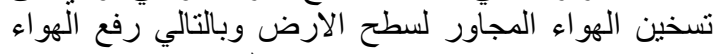
عدم استقر اريه الهو اءو التولي

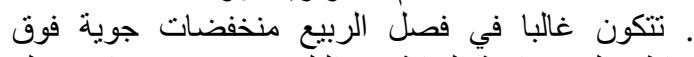

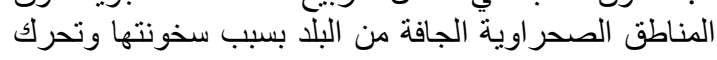

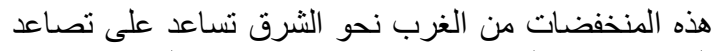

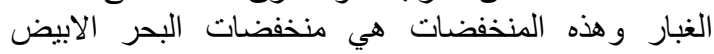
المتوسط التي تؤثر على التعراق من اجزائه الجنوبية الإنية و الجنوبية الغربية.

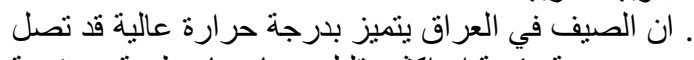

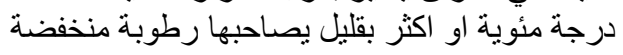

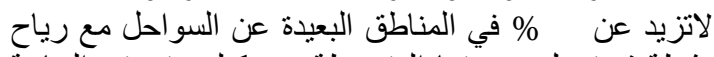

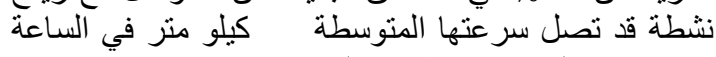
مما يساعد على حدوث ظقاهرة الغبار. و وجود مناطق مشخصة كمناطق تكوينات الكثبان الرملية مما يثكل رافدأ للعو اصف الرملية. مو اسم الجفاف المنو الية وقلة مناسيب المئة المياه في الاشهر

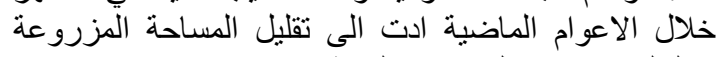

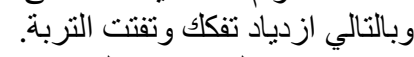

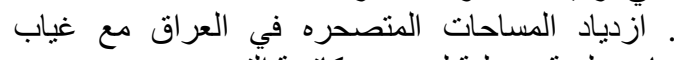

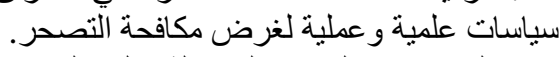

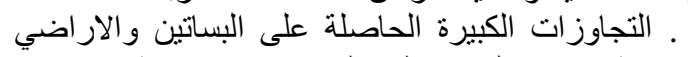

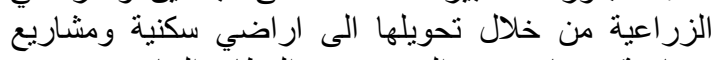
صناعية، مما يؤدي الى تدهور الغطاء النباتي وتصحر
الى ذرات يمكنها التفاعل مع الاوكسجين لتكوين الاوزون.

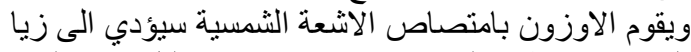
الحرارة في طبقة الستر اتوسفير ، كما يقوم بتقليل الثعة الثنمس

الاوزون بازلالة الاشعة فوق البنفسجية الضارة وعلية تعمل

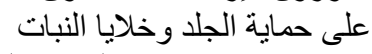

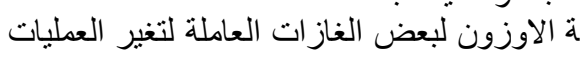

الكيميائية والتفاعلات المذكورة اعلاه مثل (cfcl3,cf2cl2) المستخدمة كدافع للايرسولاتوفي عمليات التبريد

محمد احمد حسن الطيب، محمد عبد السلام الطاهر

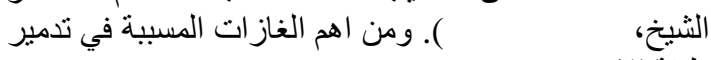
طبقة الاوزون هي:-

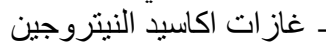

ويمكن تحديد اهم الثناثثيرات التي تحدث لطبقة الاوزون من

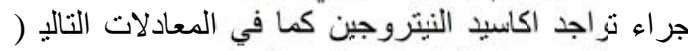

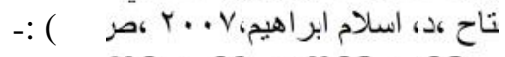
$\mathrm{NO}+\mathrm{O} 3 \rightarrow \mathrm{NO} 2+\mathrm{O} 2 \ldots \ldots$... $\mathrm{NO} 2+\mathrm{O} \rightarrow \mathrm{NO}+\mathrm{O} 2 \ldots \ldots-$

وتوضع هذه التفاعلات ان نو

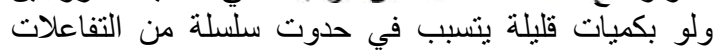
تؤدي الى تحويل الاوزون الى جزئئات اكسجين عادية بطريقة مستم الند في اجهزة التبريد والايروسولاتالتي تحمل بعض المبلة المبيدات

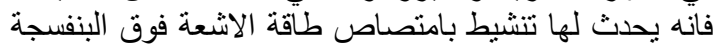

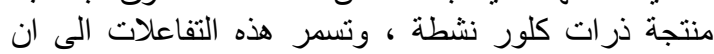

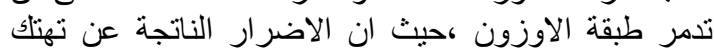
زون تؤدي الى الاصنابة بالأمراض الإنه السرطانية وخاصه سرطان ألجلا وعتمه العدسة البلورية للعين

الفصل الثاني:- تلوث الهواء في العراق المبحث الاول:- مصادر تلوث التواء في التهواء في العراق:

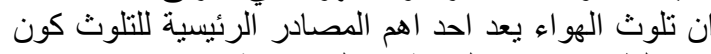

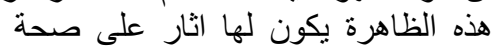

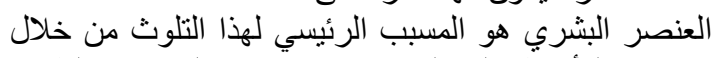

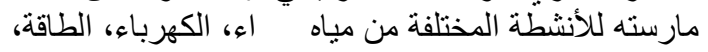

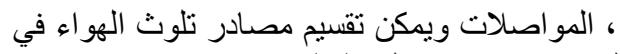

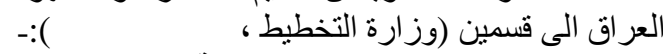
اولا:- تلوث الهواء من المصادر الطبيعة العو اصف التر ابية:

شهد العراق تغيرات مناخية خصوصا في العقد الاخير

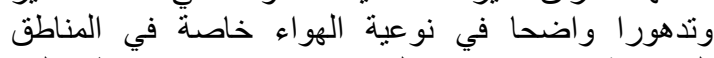

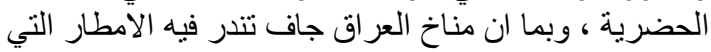

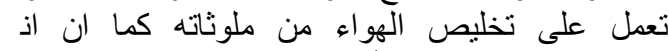

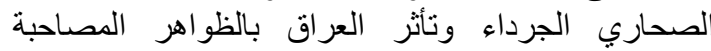

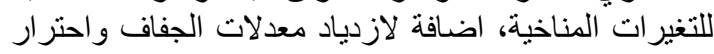

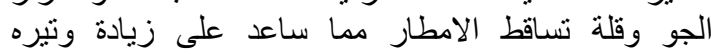

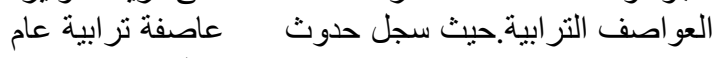
عو اصف غبارية عام 
، تلبها السليمانية يوم اما اقل المحافظات تعرضنا للعو اصف الترابية كانت دهوك فقط 2 2يوم.

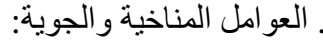

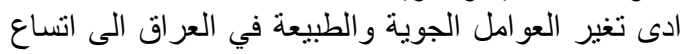

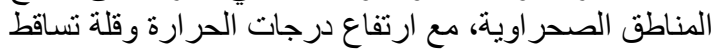

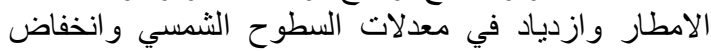

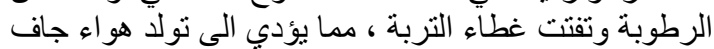

العو ا لعمليات تجفيف الاهوار دور كبير في تكون وانتشار

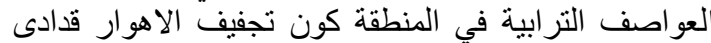
الى تفتت التربة وسكولة حملها بو اسطة الرياح.

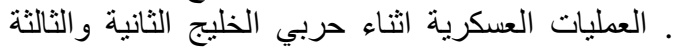

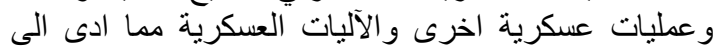
تنتت التربة مما يسرل عملية اثارتها بالرياح.

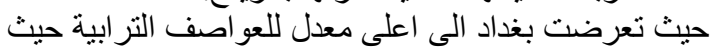

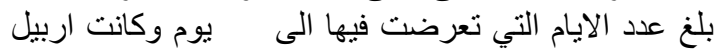

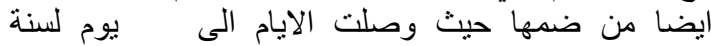

\begin{tabular}{|c|c|c|c|c|c|c|}
\hline \multicolumn{3}{|c|}{ التبخر ملميتر } & \multicolumn{3}{|c|}{ فترة السطوح الثمسي (ساعة) } & \multirow{2}{*}{ المدينة } \\
\hline$r+1 \varepsilon$ & $r \cdot 11$ & $r \ldots q$ & $r+1 \leqslant$ & $r+11$ & $r \ldots q$ & \\
\hline $\mathbf{M}$ & 7,1 & 0,0 & $\mathbf{M}$ & $v, v$ & $\Lambda, r$ & الموصل \\
\hline$\Lambda, \Gamma$ & $\Lambda, q$ & $\Lambda, \nu$ & $\Lambda, r$ & $v, q$ & $\Lambda, \uparrow$ & بغذاد \\
\hline $\mathbf{M}$ & M & $\mathrm{v}, \cdot$ & M & M & $\Lambda, \Lambda$ & الرطبة - م الربة \\
\hline $\mathbf{M}$ & 9,8 & $\Lambda, \Lambda$ & $\mathbf{M}$ & $\Lambda, 9$ & $\wedge, 9$ & البصرة \\
\hline $0, \xi$ & 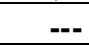 & $\varepsilon, 9$ & 0,4 &.-- & $V, \xi$ & دهوك \\
\hline $0, \mathrm{~V}$ & -..- & $\varepsilon, q$ & $0, v$ &.-- & 7,9 & زاخو \\
\hline
\end{tabular}

\section{M بيانات مفقود}

ـ وزارة التخطيط والتعاون الانمائي، الجهاز المركزي للإحصاء، تقرير الاحصاءات البيئية للعراق سنة

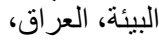

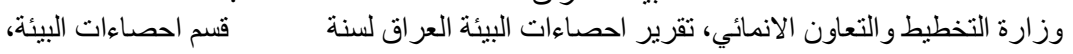

, ملميتر .و هذا يعني كلما زاد معدل

التبخر كلما ادى الى جفاف التربة وتفككها وتعرضهيا للتعرية التهاية

يتضح من خلال الجدول اعلاه ان اعلى معدل لفترة

حة ومن ثم تحولها الى صحر التربة الغكاء

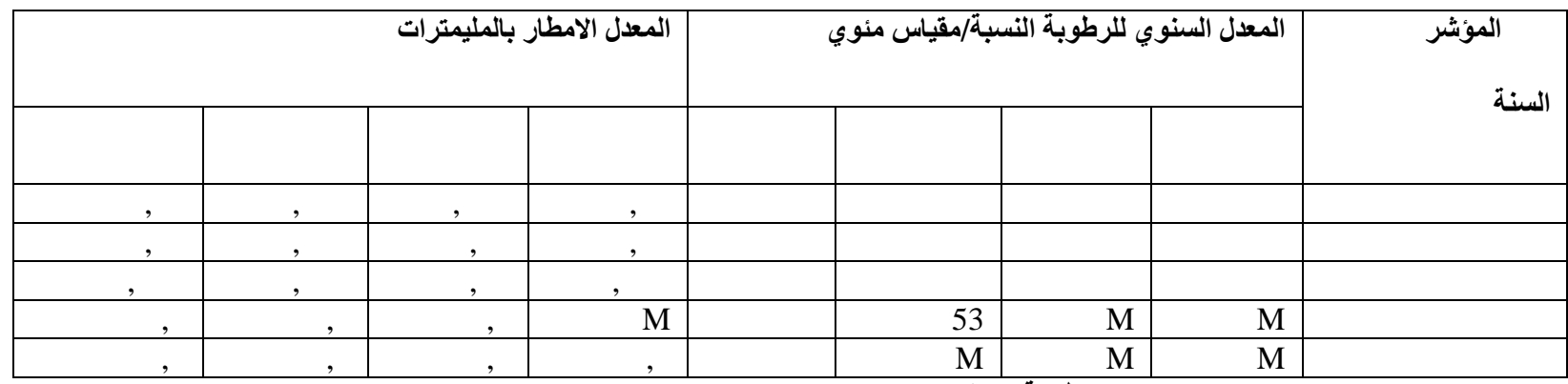

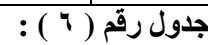

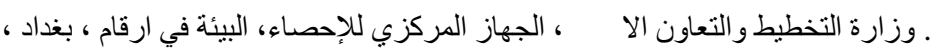

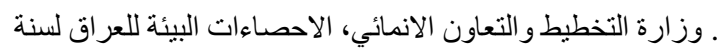

يتضح من خلال الجدول اعلاه ان اعلى معدل للرطوبة الرطوبة مع ارتفاع في معدلات الجفاف نتيجة انخفاض

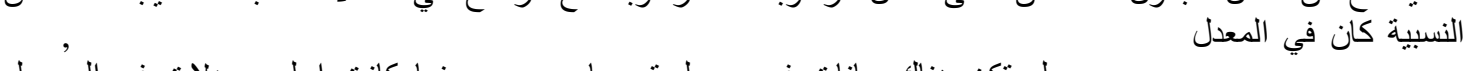
ولم تكن هناك بيانات في مليمتر عام بينما كانت اعلى معدلات في المؤصل

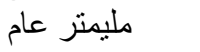

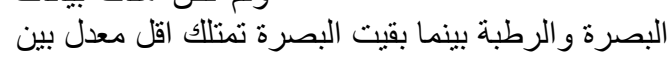

، ويمكن ان يعزى سبب ذلك ثانيا: تلوث الهواء من المصادر الصناعية 
اكاسبد الكبريت، اكاسيد الكربون، اكاسيد النتروجين

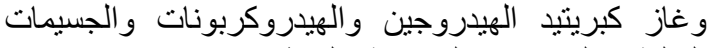

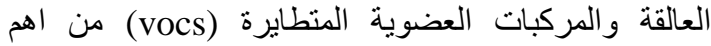

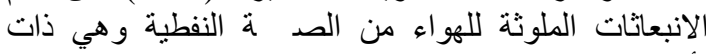
تأثثر ات بيئية.
الصناعة النفطية

$$
\text { بعد العرا }
$$

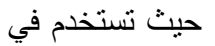

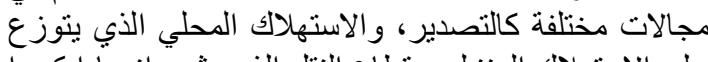

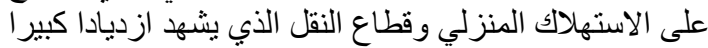

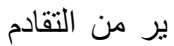

وتسري غاز ات الاحتراق معظم الانبعاثات الغازية الممثلة

\begin{tabular}{|c|c|c|c|c|c|c|c|}
\hline نفط ميان & نفط الجنوب & نفط الوسط & \multicolumn{4}{|c|}{ نفط الشمال } & \\
\hline & غاز قابل وغير قابل للاشتعال & غاز & بروبان & غاز حامض & غاز الاوكسجين & غاز حلو & \\
\hline $1,00 \cdot, \cdot \wedge, \cdots$ & $1 \cdot, \Gamma 47, \uparrow \wedge \cdot, \cdots$ & $r 0 \wedge, r \wedge r, \wedge Y r, r \leqslant 0$ & OY. & $r q q, \wedge 1 \leqslant, \cdots$ & $7 . V$ & $r q, r r q, q 4 V$ & $p+1 \varepsilon$ \\
\hline & مصفى الجنوب غاز هامضوبوني غاز الوقود غاز & مصفى الوسط غاز الوقود & \multicolumn{4}{|c|}{ مصفى الثمال } & $Y+1 \varepsilon$ \\
\hline & $19 \leqslant, \leqslant 1$. & ros,Orr,,$\Lambda$. & & & & & --- \\
\hline & غاز الجنوب غاز جاف محروق & & & سوائل ملوثة & غاز خام & غاز حامض & \\
\hline & ro, r४ ,० ४q & & & $1 \leqslant 9$ & $\circ$ & $r 1, \cdot 90, \cdots$ & $r+1 \leq$ \\
\hline & & & & & & & \\
\hline
\end{tabular}

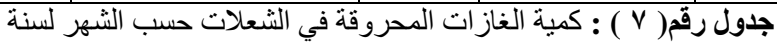

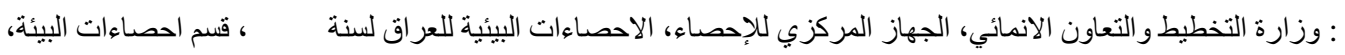

\begin{tabular}{|c|c|c|c|c|c|c|c|}
\hline g3LPPM & NO2 & NO & NOX & So2 & Eo/ppm & المحطة & السنة \\
\hline , & , & , & e & , & , & محطه الجادرية & $r \cdot 1 T$ \\
\hline , & , & , & , & , & , & محطه الوزيريه & \\
\hline , & , & , & , & , & , & محطه ساعه & \\
\hline , & , & , & , & , & , & محطه ابو ختساوي & \\
\hline , & , & , & , & , & --- & محطه جامعه بابل & \\
\hline--- & , & , & , & , & , & محطه المتحركة & \\
\hline --- & , & --- & --- & , & , & محطه خور الزبير & \\
\hline --- & , & , & , & , & , & محطه باب ابيض & \\
\hline , & , & , & , & , & , & محطه الوزيرية & $r+1 \leq$ \\
\hline , & , & , & , & , & , & محطه ساحهd & \\
\hline
\end{tabular}

جلول رقم (^) : تركيز الملوثات في الهو اء المحبط في المناطق الحضرية.

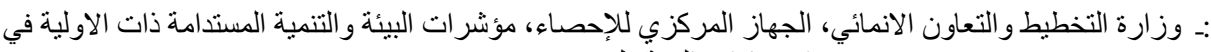

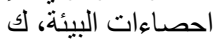

كهربائية حيث تفتقر محطات الكهرباء الحرارية والغازية

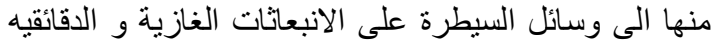

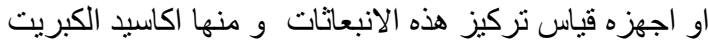

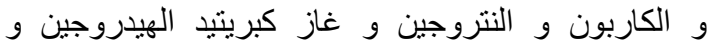

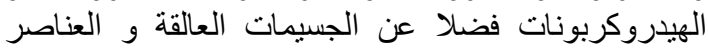

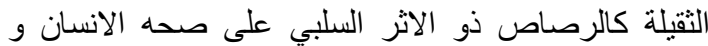

البيئة.

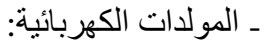

ان استمرار النقص في امدادات الطاقة الكانة الكهربائية

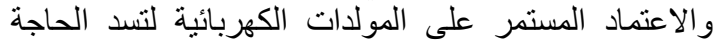

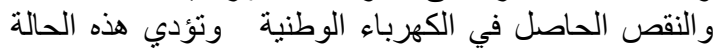

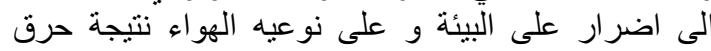

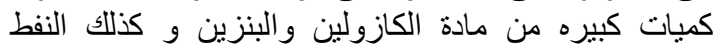

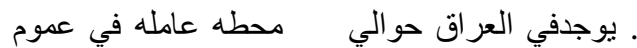

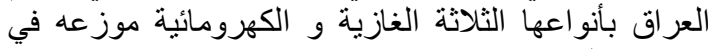

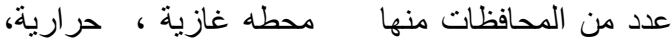




\begin{tabular}{|c|c|c|c|c|c|}
\hline \multicolumn{3}{|c|}{ /مايكرو غر ام/ } & \multicolumn{3}{|c|}{ تر اكيز مايكرو غرام/ } \\
\hline & & & & & \\
\hline , & --- & --- & , & --- & $-\ldots$ \\
\hline
\end{tabular}

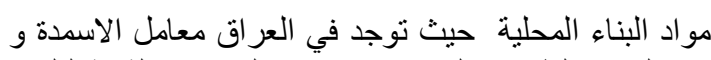
الاسفلت و الطابوق التي تعد من أهم المصادر الثابثة التابتة لتلوث

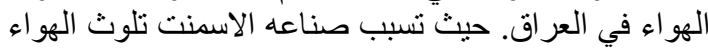

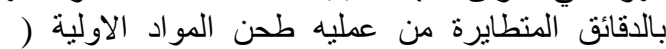

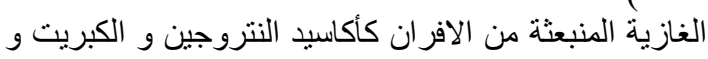

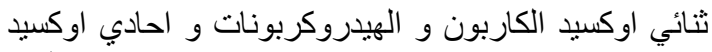
كاربون وغيرها من نواتج الاحتراق (وزارة البيئة

ناعات الانشائية، كونها تطلق العديد من الملوثات

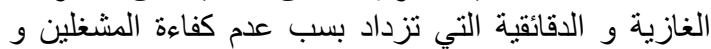
استخدام النفط الاسود الذّي يزيد من الانبعاثات الضات الضارة سيما

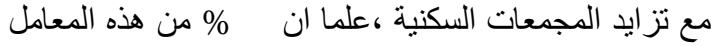

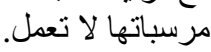

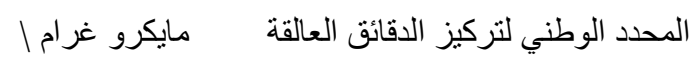

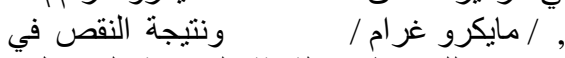

البيانات تم احتسابها للمحافظات الثلاثة الرئيسية الموصل فئل فئل

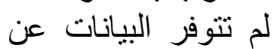

البصرة حيث كانت بغداد اعلى من الموصل في تركيز

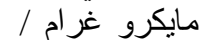

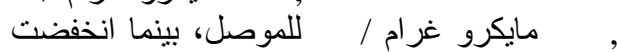

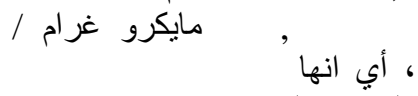

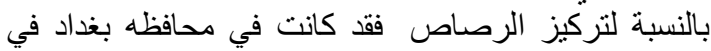
حالة ارتفاع مستمرة و لم تتوفر بيانات اخرى عن محافظة

ـالصناعات الانثائية

يثهد العراق نموا سكانيا و عمرانيا نشائية با

\begin{tabular}{|c|c|c|}
\hline السلبيات المؤثرة & عدد المعامل & اسم النشاط \\
\hline \multicolumn{3}{|l|}{ جميعها تعمل بالوقود الردئ } \\
\hline \multicolumn{3}{|l|}{ جميعها مخالفه للمحددات الموقعية و المتطلبات البيئة } \\
\hline اغلب المعامل لاتوجد فيها منظومات حرق و ان وجدت غير كفو وة & & معمل الطابوق في ميسان \\
\hline ت تتوفر منظومه حرق اليه الا انها لا ان تشتغل دائما & & معمل الطابوق في قادسيه \\
\hline \multicolumn{3}{|l|}{ مخالفه للمحددات البيئة } \\
\hline مخالفه للمحددات الموقعية و تقنتقر الى وسائل للحد من الانبعاثات الغازية و الدقائقبه & & معمل الاسفلت في القادسية \\
\hline \multirow[t]{2}{*}{ 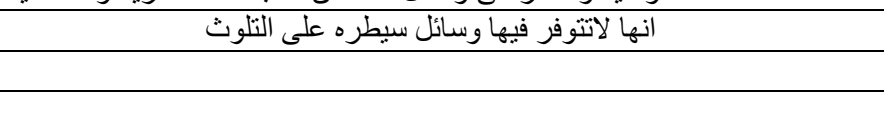 } & & الاسفلت في التاميم \\
\hline & & معمل سمنت كبيسه \\
\hline & & \\
\hline & & \\
\hline \multicolumn{3}{|l|}{ جميعها تعمل ولكن مرسبات الغبار عاطلة } \\
\hline & & 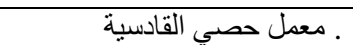 \\
\hline المعمل يعمل & & ـ معمل السر اميك في الرمادي. \\
\hline تتصناعد الأبخرة من بعضها لعدم وجود وسائل سبطر عليها. & & انتاج الطفونيك في الآنبار \\
\hline
\end{tabular}

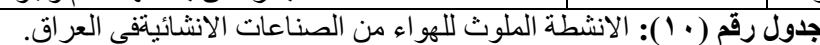

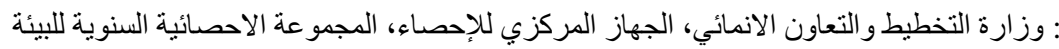

ان من اهم الملوثات الهو ائية الناتجة من هذه الصناعة هي

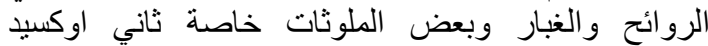

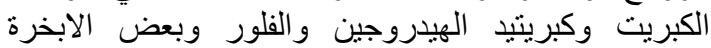

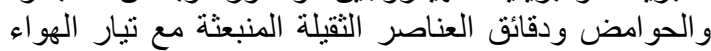

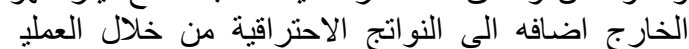

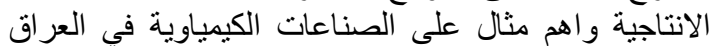

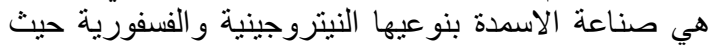
تتبعث منها انواع مختلفة من ملوثات الهواء حسب نورعة نوع

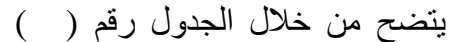
المحافظة بغداد يعمل بالوقود الرديء وفئ وهذا ما يجعل الهواء

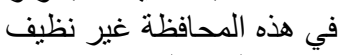

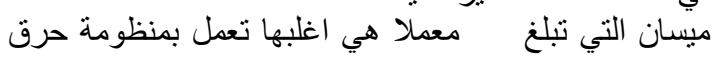

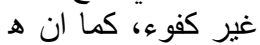
يوجد منه مرسبات للغبار و هذا ما يتبين التنوث الحاصل في الهو اء في العراق. ـالصناعات الكيمياوية و الاسمدة الكيمياوية: 
الغاز الجاف كماده مغذية عدا مصنع المنظفات الذي يعتمد كيروسين و الريفورميت كماده مئة عنداد مغذية.

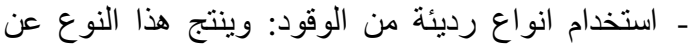

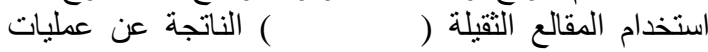

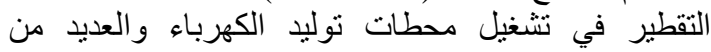
المجالات ألصناعية الاخرى وحتى على مستوى الافران الحجرية للذ الذ الذ
كما تنتشر الدقائق الماديةمن عنصر

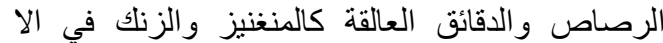

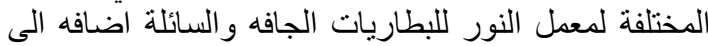

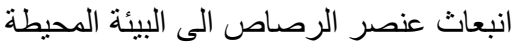

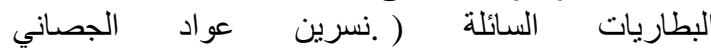
اما البتروكيمياوت و الاسمدة تعتمد على النى

\begin{tabular}{|c|c|c|c|c|c|c|c|}
\hline \multicolumn{3}{|c|}{ مصفى الوسط } & \multirow{2}{*}{ غاز الجنوب } & \multirow{2}{*}{ غاز الشمال } & \multicolumn{2}{|c|}{ مصفى الجنوب } & \multirow{2}{*}{ المؤشر } \\
\hline نفشا & زيت الغاز & زيت الوقود & & & غاز الوقود & زيت الغاز & \\
\hline , & , & , & & & , & , & \\
\hline
\end{tabular}

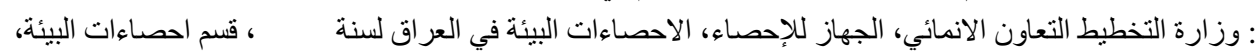

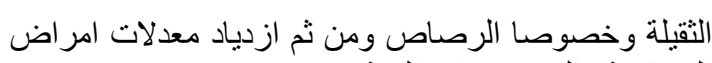
البساسية و الربو (وزارة البيئة ، ، r. التغير ات المناخية

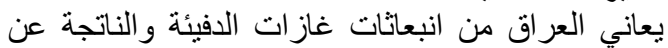

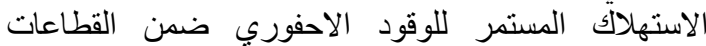

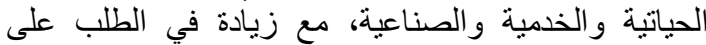
الوقود كتلبية منطلبات النقص في امداد الطُاقة الكهربائية

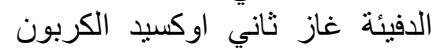

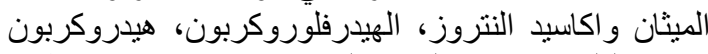

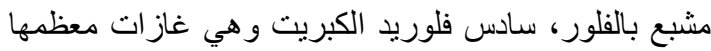

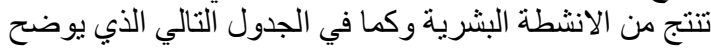

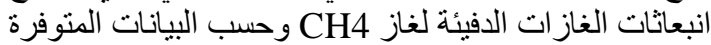

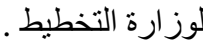

\section{ثالثا: تلوث الهواء من المصادر المتحركة}

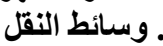

يعد قطاع النقل البري احد ابرز الانشطة التي تسهم في

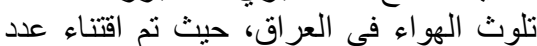

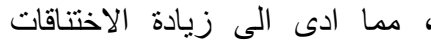

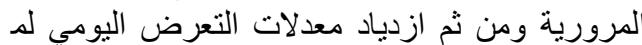
الهو اء الناتجة من عو ادم السيار ات وزيادة التهاد الطلب علّى الوقود.

الاخيرة حيث تجاوز ملايين مركبة وهو المصدر الرئيسي

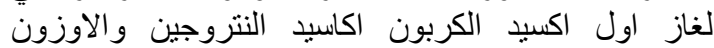

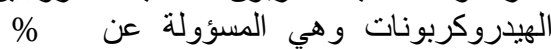

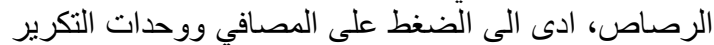

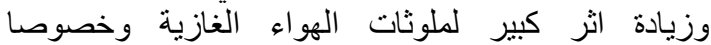
الهيدروكربونات و اكاسيد النتروجين والكربناء الكربون و العناصر

\begin{tabular}{|c|c|c|}
\hline CH4 & المحطات & السنة \\
\hline , & الجادرية & \\
\hline , & الوزيرية & \\
\hline , & & \\
\hline , & & \\
\hline , & & \\
\hline , & الوزيرية & \\
\hline , & & \\
\hline
\end{tabular}

جلول رقم (r ا ( ): انبعاثات الغازات الدفيئة.

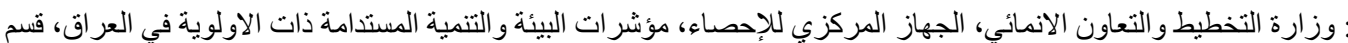

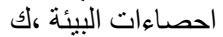

العراق هو البلد الذي لا ينتج مو اد مستنفذه لطبقة الاوزون

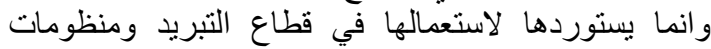

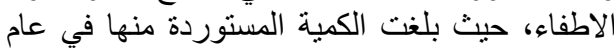

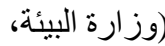

حيث تتضح من خلال الجدول اعلاه ان اعلى معدل لغاز , تلبها

$\mathrm{CH} 4$

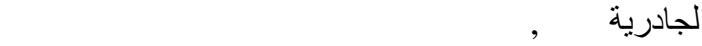
محطة الوزيريه اقل من الاندلس وهذا يعني ارتفاع انبعاثات

$\mathrm{CH} 4$ 


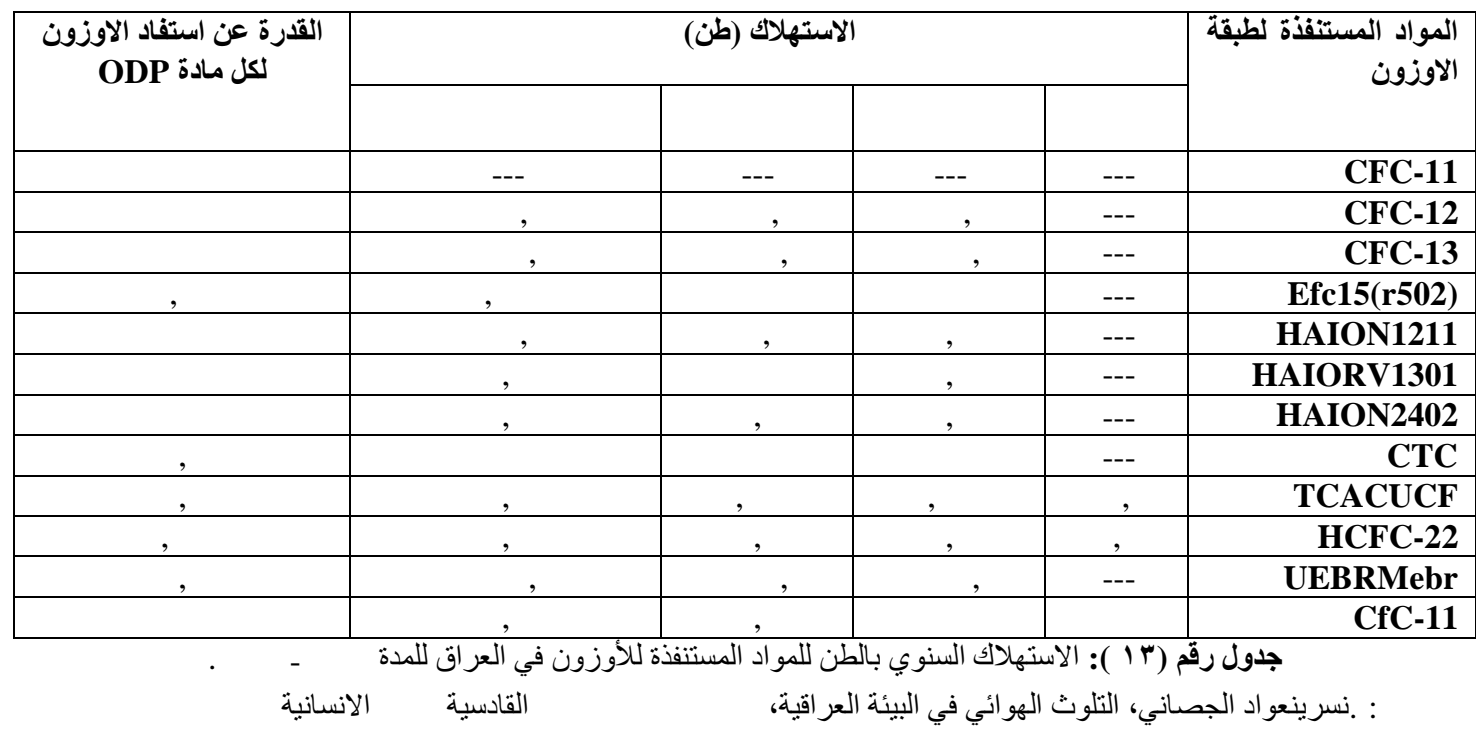

منه تحمل محل

$$
\text { البيئة في وزارة العامة للبيئة البشرية. }
$$

حماية وتحسين البيئة رقم( ) الذي يهدف الى حماية البيئة من

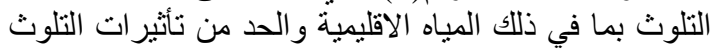
هتمام التاريخي القديم بالبيئة

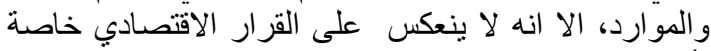

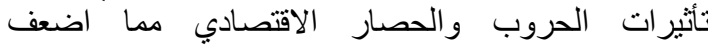

دخل العراق مرحلة جديدة من تاريخه

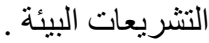

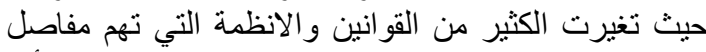

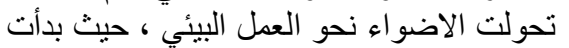

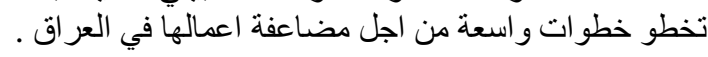
على رسم السياسة البيئة لضمان حماية البيئية من التلوث

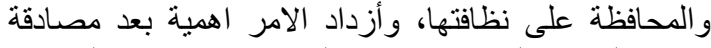

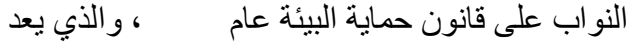
اكثر القوانين الهية في معالجة المشكلات البيئة التي يعاني ولئي

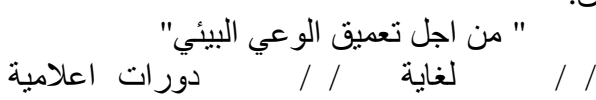
منها العراق. - منز لوزارة البيئة التي اصبحت مستق العديد من الاتفاقيات الدولية البيئية منها، اتفاقية الامم المتحدة

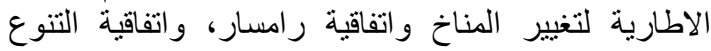

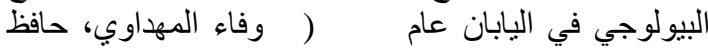

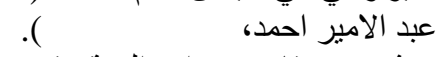
ثم صدر قانون وزارة البيئة رقم ( ) ( )

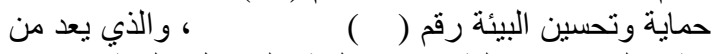

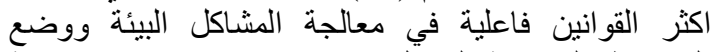

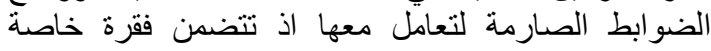

يتضح خلال الجدول اعلاه ان نوع ونسبة المواد

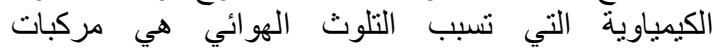

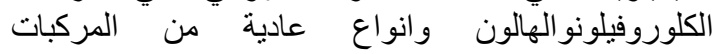

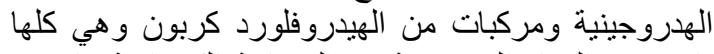

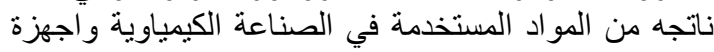

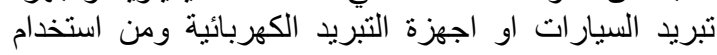

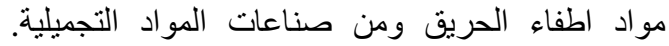

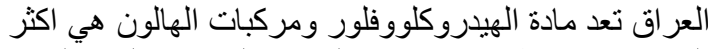

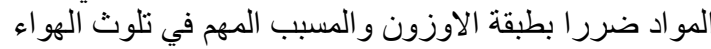

الحروب والمعارك و واستخدام القتابل الكيمياوية و المواد

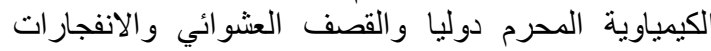

(HCFCS)

\section{CFCS}

العناية بالثعر ، فقد ارتفعت من<smiles>[VH][TlH]</smiles>

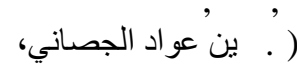

المبحث الثاني: استراتيجية الدولة في الحفاظ على البيئة من الن التئ

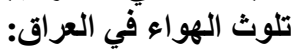

تجسد الاهتمأم بشؤون البيئة وحماية الموارد الطبيعة محليا

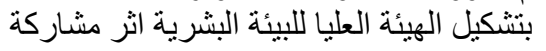

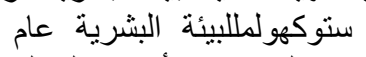

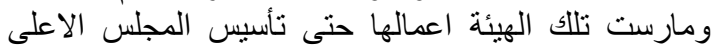
للبيئة البشرية عام البشات استحداث المديرية العامة للبيئة البشرية في العام نفسة في بهرف حماية البيئة ومنع تلوثها، كما تأسست دائرة حماية وتحسين 
العراق، والتوعية البيئية، ودعم قدرات الحكومة في مجال

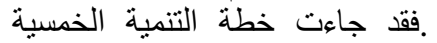
لتكرس من اهمية ادماج البعد البيئي مع الخئية

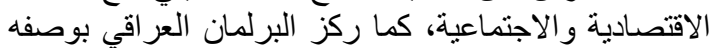

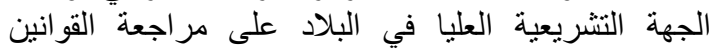

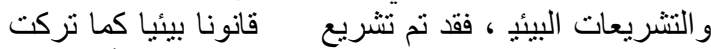
تشريعات مقترحة الى البرلمان يتخذ القرار بشأنها وكان لانطلاق ومنها التشريعات التخان
بتأسيس شرطة بيئية

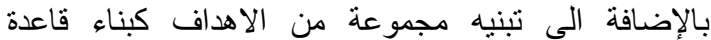

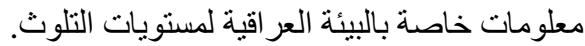

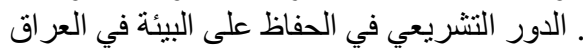

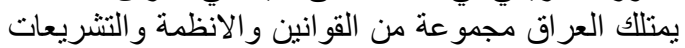
التي يمكن ان تسهم في المحافظة على الينه اليئة

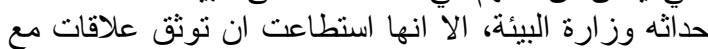

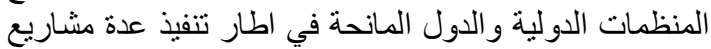

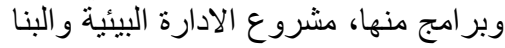

الاوزون الوطنية، والادارة الطبيعية والثنفافية لا هوار

\begin{tabular}{|c|c|}
\hline التشريع - لميع & 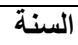 \\
\hline قانون وز ارة البيئة رقم & \\
\hline قانون حماية تحسين البيئة رقم & \\
\hline نظام المحددات الوطنية لاستخدام مياه الصرف الصحي المعالجة في الري الزراعي رقم & \\
\hline نظام حماية الهواء الدحيط من التلوث رقم ( ) & \\
\hline 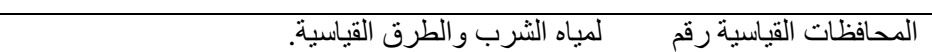 & \\
\hline تعليمات صحية تتعلق بيئة العمل. & \\
\hline
\end{tabular}

جدول رقم ( \& () : التنثريعات البيئية في العراق.

: وزارة البيئة ، وتوقعات حالة البيئة في العراق ، العراق،

بر امج لاستخدام الطاقات المتجددة وخاصة الثمسية وتحسين

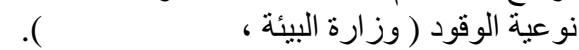

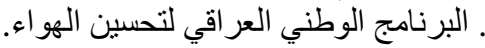

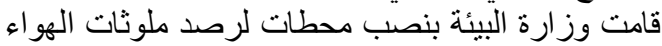

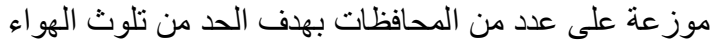

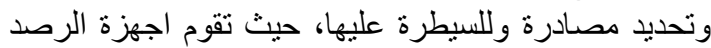

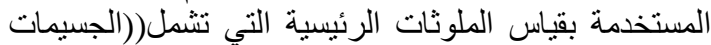

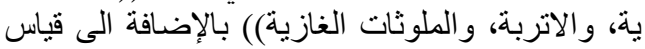

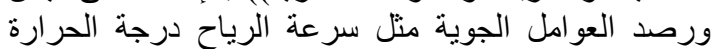

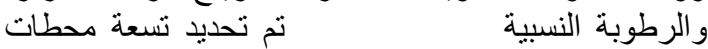

واذا ما تناولنا مسار خطة التنمية الوطنية وهي اول خطة تنموية في الإنية

ومحدد على الاستدامة البيئية للتنمية من خلال تعزيز التتمية

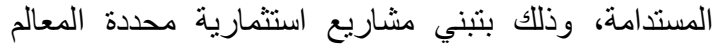

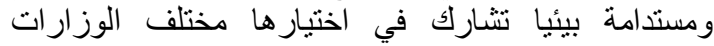
واستخدام تكنولوجيا حديثه بيئية في معالجة المصادر المحددة مجال حماية نوعية الهو اء يتم ذلك من خلال تحقيق

العشوائي واستخدام النفايات الصديقة للييئة في الانشطة الصناعية الكبيرة ومحطات نوليد الطاقة الكهربائية و

\begin{tabular}{|c|c|c|}
\hline طبيعة موقع المحطة & اسم المحطة & المحافظة \\
\hline منطقة سكنية مرورية & الوزيرية & \\
\hline \multicolumn{3}{|l|}{ منطقة سكنية خدمية مرورية } \\
\hline منطقة سكنية & 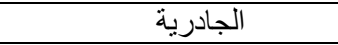 & \\
\hline منطقة سكنية & (موقع مديرية بيئة الموصل) & \\
\hline منطقة خدمية & 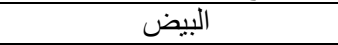 & \\
\hline \multirow{2}{*}{\multicolumn{3}{|c|}{ منطقة صناعاعية }} \\
\hline & & \\
\hline منطقة سكنية & موقع مديرية بيئة البصرة & \\
\hline منطقة صناعبة & منطقة خور الزبير & \\
\hline
\end{tabular}

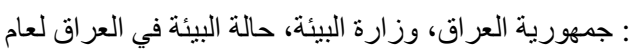

حطات هي الوزيرية

الجادرية، و الاندلس، ويمكن توضيح اهم التراكيز الدسبية في تلوث الهو اء وكما في الجدول التالي 


\begin{tabular}{|c|c|c|c|c|c|c|c|}
\hline غرامائق العالقة مايكرو & الاوزون & الكادي اوكسيا & ثنائي اوكسيد & ثنائي اوكسيد & $\begin{array}{c}\text { Nuhc } \\
\text { الهايروكربونات }\end{array}$ & السنة & المحطة \\
\hline & , & , & , & , & , & & الوزيرية \\
\hline & , & , & , & , & , & & الجادرية \\
\hline & , & , & , & , & , & & الاندلس \\
\hline
\end{tabular}

$\therefore$ TSP

الاحفوري خاصة وقود الديزل ، وينبعث من وسائل النقل

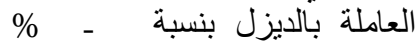

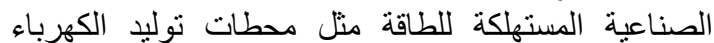
وكذلك صناعة الاسمنت لها اثار على الصحة وقد تؤدي الى الى

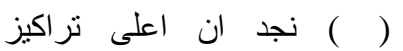

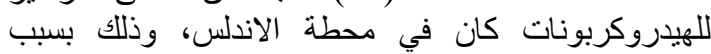
الكهرباء ووسائط النقل التي تتميز بها

المنطقة بالكثافة المرورية المستثفيات، اما بالنسبة لثنائي اوكسيد النتروجين فكان اعلى

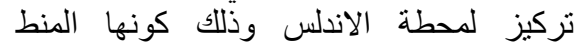
مروريأبمولدات الديزل الألا في منطقة الجادرية فقد ارتفع الإنع

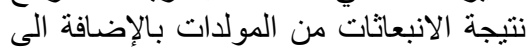

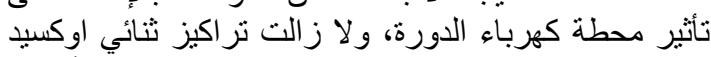

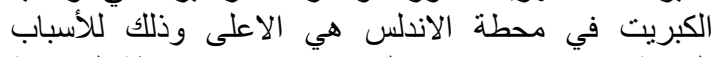

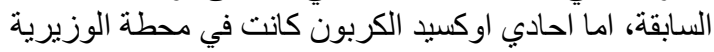

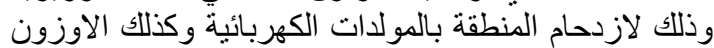

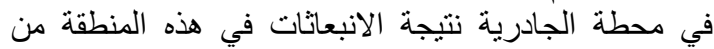
محطة كهرباء الدورة.

$$
\text { التراكيز هي محطة الوزيرية لعام }
$$$$
\text { العو اصف النتر ابية. }
$$

توجد في محافظة بابل محطتين لمراقبة تلوث الهواء هي ي ومحطة جامعة بابل و وهما منطقتين لإنين صناعيتين وكما في ألجدول التالي.
في البداية يجب ان نوضح ان هذه المركبات تنتج من عدة

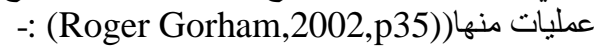

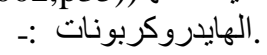

الداخلي وعمليات تكرير النفط في وتئي

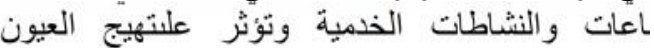
و الرئتين و المجاري التنفسية. • ثنائي اوكسيد النتروجين(NO2): تنتبثت في الهواء من مصادر طبيعة مثل تحلل المركبات المتنوعة عن النتروجين البشرية مثل احتراق الوقود بالسيارات ومحطات الكهرباء

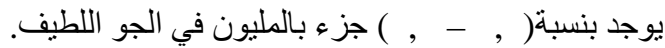
. ثنائي اوكسيد الكبريت SO2 :- ينولد من احتراق الفحم قائة او في وحدات التدفئة المنزلية

من صنع الورق والتعدين والنفط، من اثاره يعمل على التئي تخديشالأغشية المخاطية مبدأ السعال و والالم الصدر و والتهاب التهاب

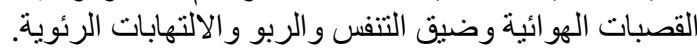

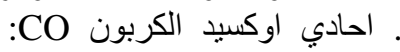

ومصادر ألتذفئة و التندخين وتسهم السيار ات وحدها

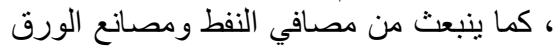

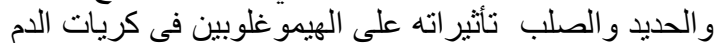
الحمر اء وله قدرة على التشتت تزيد التيد بحو الي

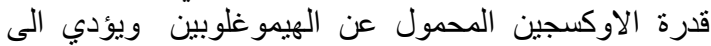

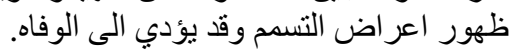

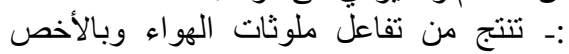

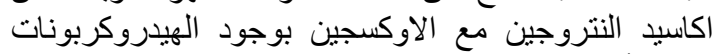

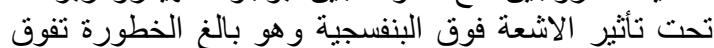

\begin{tabular}{|c|c|c|c|c|c|c|c|}
\hline مايكرو غرام/املقّ العالقة & الاوزون & الكركسئ & الكبريتي & النتروجيدي & $\begin{array}{c}\text { Nmthc } \\
\text { الهيدروكريونات }\end{array}$ & السنة & المحطة \\
\hline & , & , & , & --- & , & & ابو ختساوي \\
\hline & , & & , & $\begin{array}{l}--- \\
---\end{array}$ & , & & جامعة بابل \\
\hline
\end{tabular}
سميته مركبات اول اكسيد الكربون و السيانيد.

جدول رقم (V) ): المعدلات السنوية لتر اكيز مختلفة.

: وزارة البيئة، حالة البيئة في العراق لعام 
الإذابة وهذه التقنية اكثر كفاءه من سابقتها و عادة ماتستخدم

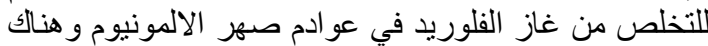

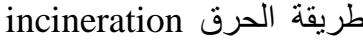
العضوية وغازي ثاني اكسيد الكبريت وكبريتيد الهيدروجين وتحويلها الى ثاني اكسيد الكربون وماءئ (ruthE,weiner and robin)

(Mathews,2003,pp399-404) ـ يمكن استخدام انواع للسبطرة على الجسيمات الدقيقة، حيث توجد العديد من التقنيات تمثل المرسبات العبد الالكترونية

Eleclrostaticprecipititory الاعصارية cyclonefilters

fabric filters والمرشحات الليفية collectorswet (j,jefireypeirceat at,,1997,pp299,345)

نوعية الهو اء معزر نظام الانذار المبكر من حوادث الملوثات.

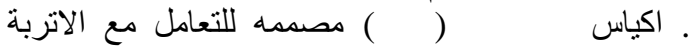

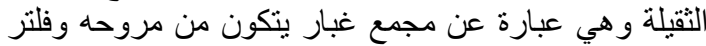

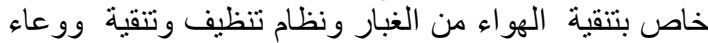

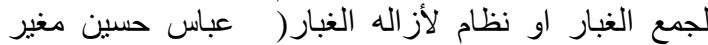

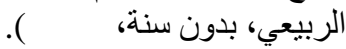

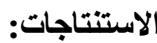

ل الهواء من اساسيات الحياة و انقطاعها لدقائق يعد كافيا لهولك الانسان.

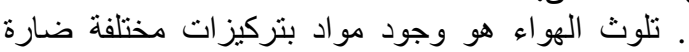
للإنسان وللحيو ان و النبات و التربة و والبيئة.

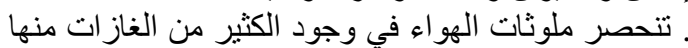
اكاسيد الكاربون اكاسيد الكبريت اكاسيد النتروجين، كبريتيد

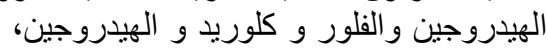
الجسيمات العالقة. ـ يؤدي تلوث الهواء اللى اثار على الانسان الأنسان و على البيئة و

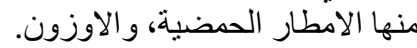
. عانت البيئة العراقية من مصادر الاوزية ثلوث الهونة الهواء و منها

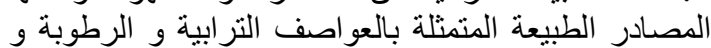
النفطية و المولدات الكهربائية و الصناعات الانشائية و الكيمائية و الاسمدة.

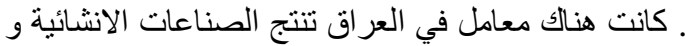
جميعها و اغلبها لاتتوفر فيها مرسبات في الغبات الغبات

. كما ساهمت ازدياد اعداد المركبات في السنوات الأخيرة

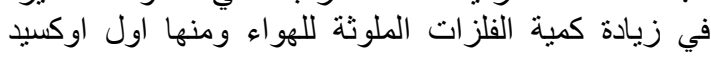

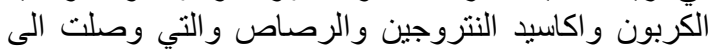
$\%$ ت تم استتفاد طبقه الاوزون ستخدام القتابل الكيماوية و القصف العشو ائي و الانفجار ات تن تضمين البعد البيئي في خطط التنمية الا انها لم تجد. صداها. ـ كان هناك برنامج مر اقبه لتحسين نوعيه الهواء الا انه

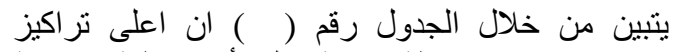
الهيدروكربونات في محطة جامعة بابل لأنها منطقة صنان صناعية اعنية

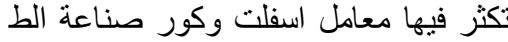

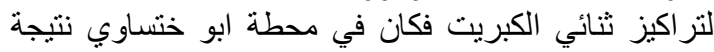

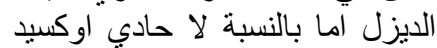

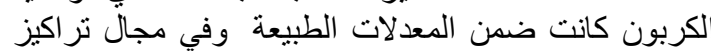

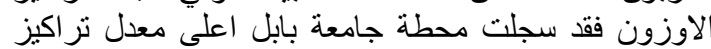

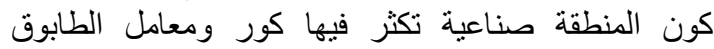
وكان اعلى تركيز للاقائق العالقة في محطة جامعة فئة بابل وذللك لقربها من الثارع الثركز العام الذي يكون مزدحم مروريا.

$$
\text { بناية مديرية بيئة الموصل ووجدان }
$$

نموذج يومي لقياس الدقائق العالقة في الهو اء

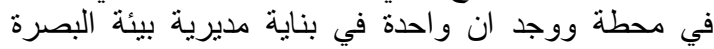

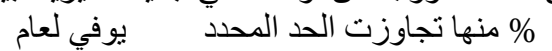
. اساليب الدولة في السيطرة على تلوث الهد الهو اء في العراق.

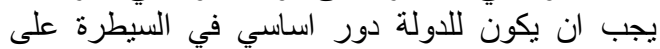

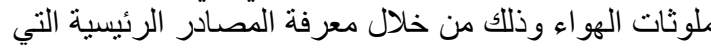

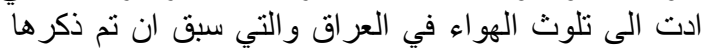

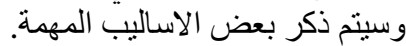

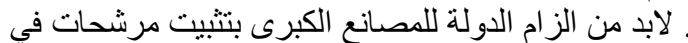

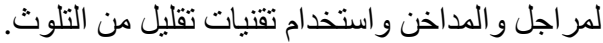

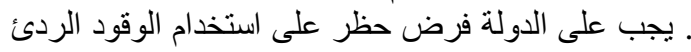

$$
\text { التجارية. }
$$

الزام الدولة للمخابز و المطاعم ومواقد الثواء بتثبيت

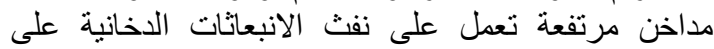
الاقلاعلى بمترين من البناية ليسهل تشتئ نفي الادخنة مع الرياح

. استخدام اليات تنظيف حديثة يسهل تقليل من الغبار

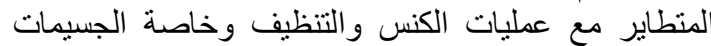

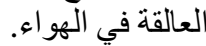

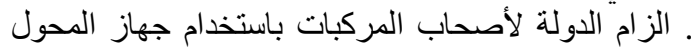

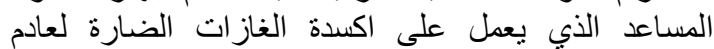

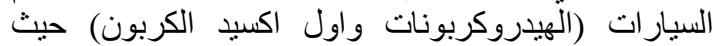
غير الكاملة عبر خلايا المحول الذبون الذي الذبات

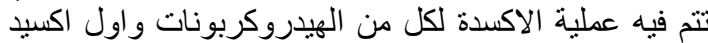
الكربون الغازين وتحويلها الى ثاني اكسيد الاكيد الكربون وبخار

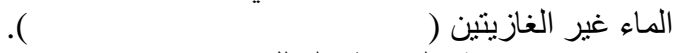

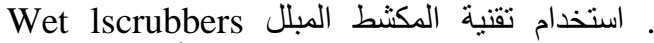
من خلال غسلها و أذابتها في محاليك

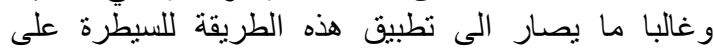
تركيزات غازي ثاني اكسبد الكبريت وثانياني اكسبد النتروجين

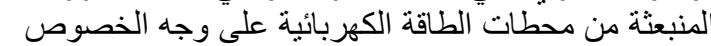

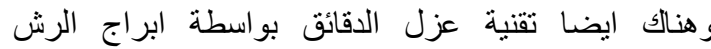
paclcedserubbers زجاجية تمرر فيها الملوثات الغازية ويتم عزلها بواسطة 


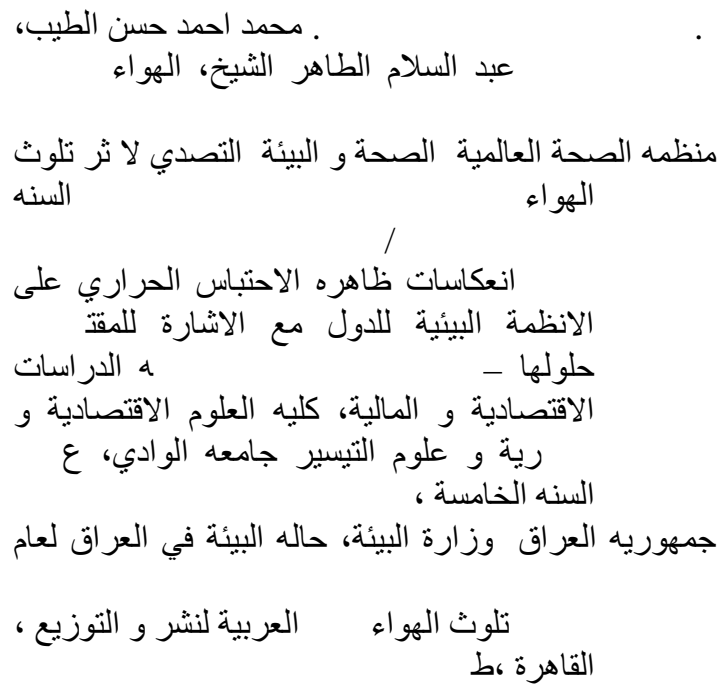

Ruth E., weiner and Robin A., mathews, Enviroment at Engineering, 4thed,
هناك تحديات كبيره من اجل التقليل من تلوث

الهو اء في العراق.

التوصيات

الترق الرقابة على المنشآت الصناعية و الزر اعية و أي مصادر

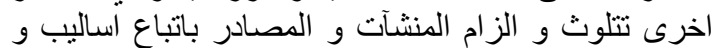

نظم الانتاج التطبيقية و عدم السماح بتسرب ملوثنات الهواء الهاء

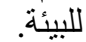

ـ نشر الوعي البيئي لدى افراد المجتمع من اجل سلامه الهو اءو نقائه فالهو اء ألنقي يعني بيئة سليمه.

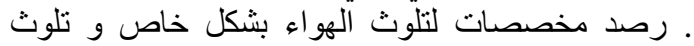

البيئة بشكل عام في الموازنة العامة للاولة من اجل التقليل من التلوث البيئي.

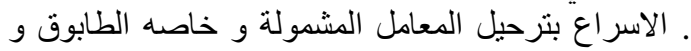

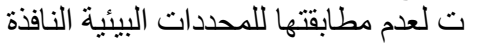
ـ فتح افاق التعاون الدولي و الاستفادة من المؤسسات الباتئية البحثية و الجامعات لبناء الامكانيات الوطنية من اجل تحديد السبل البولئ

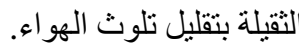

ـ زياده المسافات الخضر اء في داخل المدن و المحافظات

على البيئة و جماليتها. ـ تفعيل دور الرقابة البيئية على النشاطات المختلفة الملوثة

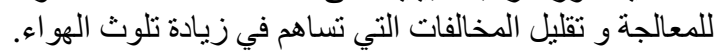

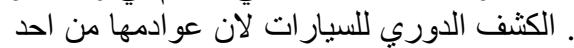

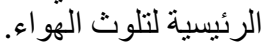

ـ تطوير وسائل التخلص من القمامة و النفايات و خاصده تلأك التي ثم حرقها في الهو اءو و التي تزيد التلوث. ـ الدجمعات الميكانيكية التي تعمل على تنقيه التيه الهواء من

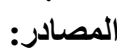

ـ وفاء جعفر المهاوي حافظ عبد الامير امين التحديات

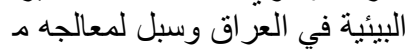
الالمانية، مجله العلوم الاقتصادية السنه

جمهوريه العراق وزارة البيئة الاستراتيجية الوطنية لحمايه البيئة في العراق و خطه العمل التنفيذية لفتره

، دراسة تحليله للبيئة و

المواجه، دراسة تحليله، كليه العلوم جامعه الاز هر.

مجله الوكالة الدولية للطاقة الذرية، جودة الهواء و الصحة،

www, who,int/mediacentre/factshats,fs

313lar

ـ محمد حسين عبد القوي لوث البيئي،مركز الاعلام

ابحاث البيولوجية للمناطق الحارة، الامطار الحامضية

و نأثيراتها البيئية و الصحية، الصئ، جامعة بغداد ، كليه ، نشرة التوعية العلمية الثهرية الثالثة 
mengeshaadmassu, Airpollution, university of Gondar, (2006).

dr. geoff, dr. binjalaludin, dr. vickysheppeard, Air pollutioneconomics health costs of airpollution in thegreater Sydney metropolitan region, (2005).
Buiter worth Heiheman, Newyork, (2003).

J., Jeffrey peirceetd, Environmentod pollution and ccntorl, 4thed, Elsevier science and technolcgy Book, Newyork, (1997).

air pollution from ground transportation, united nations, (2002). Roger Gmorha

\title{
The state's role in the protection of air pollution in Iraq
}

\author{
Muntadar Fadhel Saad
}

\begin{abstract}
Air pollution means the situation where the air contains materials with concentrations to be harmful for people or environmental. The most prominent source of pollution in Iraq resulted from war's years where several missile were used. In addition, burning refinery and houses as well as constructive industries resulted in production of several harmful polutants. Als, electricity generators which used fossil fuels increased and caused releasing of high concentration of $\mathrm{CO}_{2}$ in the air. Increased the number of cars after 2003 led to the increase in used fossil fuels and it represented an important source of polutants.
\end{abstract}

